DIVISION OF THE HUMANITIES AND SOCIAL SCIENCES

CALIFORNIA INSTITUTE OF TECHNOLOGY

PASADENA, CALIFORNIA 91125

ENDOWMENT EFFECT THEORY, SUBJECT MISCONCEPTIONS AND

ENHANCEMENT EFFECT THEORY: A REPLY TO ISONI, LOOMES AND SUGDEN

Charles R. Plott

Kathryn Zeiler

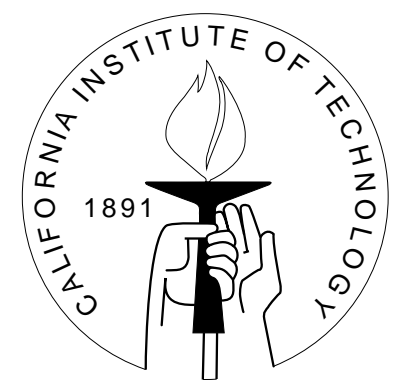

SOCIAL SCIENCE WORKING PAPER 1321

May 2010 


\title{
Endowment effect theory, subject misconceptions and enhancement effect theory: A reply to Isoni, Loomes and Sugden
}

\author{
Charles R. Plott Kathryn Zeiler
}

\begin{abstract}
None provided
\end{abstract}

JEL classification numbers: C91, D11

Key words: 
Endowment Effect Theory, Subject Misconceptions and Enhancement Effect Theory: A Reply to Isoni, Loomes, and Sugden

Charles R. Plott and Kathryn Zeiler

April 15, 2010

The purpose of Plott and Zeiler (PZ) (2005) was to investigate whether previously published experiments using consumption goods such as mugs and candy bars to measure gaps between willingness to pay (WTP) and willingness to accept (WTA) support endowment effect theory (EET). Our results demonstrate that the gap for commodities can be turned on and off by implementing procedures designed to control for subject misconceptions about the value elicitation procedures. Although our purpose was limited to that narrow focus, ILS claim that our purpose was much broader. Here we make clear that our focus was clearly stated and that the conclusions of our paper are supported by all of ILS's and our data.

Following experiments traditionally used to demonstrate the endowment effect, we used mug valuations to test EET. We used lottery rounds only to provide our subjects with paid practice using the value elicitation device prior to employing that device to elicit subjects' mug valuations. In our paper, we provided no detailed analysis of the lottery data, and the absence of any detailed analysis of those data forms the foundation of the ILS paper and the discussion in this Reply. In a footnote, we reported evidence of contamination in the lottery data that rendered it inappropriate for our purposes. (PZ, 2005, fn. 15) Our footnote summarized the details of misconceptions reported in a data supplement provided to all who request our lottery data. The supplement was not referenced in our paper; we include it here as Appendix 2.

ILS claim that our 2005 paper is misleading and has misled researchers. They are concerned that our paper produces, and has been interpreted as producing, a set of procedures sufficient to remove all gaps, including gaps in lotteries. To justify their concern, they focus on the wording of our abstract and overlook the context of paragraphs from which they quote sentences to support their thesis. The result is what we consider to be a misleading picture of the content of our paper and the facts that we report, namely that mug gaps disappear after we implement controls for misconceptions and that none of our data provides support for EET. We want to 
emphasize that our focus was on EET and not on more general theories of preference formation, reference effects and decision processes that have emerged in the literature more recently and might explain our results. ${ }^{1}$ In Section 1, we demonstrate that we did not make broad claims about our procedures.

ILS make three additional claims. First, they claim that endowment effect theory "appears to be a loosely-related family of theories..." (ILS, p. 8) From their immediately subsequent discussion, one might infer that testing EET is a futile endeavor. In Section 2, we demonstrate that endowment effect theory is well-specified and makes clear predictions given our experimental environment. We also emphasize that ILS's and our mug data do not support EET. When controls for misconceptions about the elicitation device are implemented in mug experiments, the valuation gap disappears.

Second, rather than focus as we do on EET, ILS substitute their own, much different focus: to determine whether our procedures generally eliminate gaps. ILS recognize that our procedures contaminated the lottery data and attempt to adjust our procedures to control for all contamination that concerned us. Their understanding of the sources of contamination, however, is much narrower than ours. In Section 3, we demonstrate that, despite their attempt to implement a complete set of controls, ILS's lottery data are contaminated in the ways we described in our paper (PZ 2005, footnote 15) and in our data supplement. A closer look reveals that ILS's lottery data contain obvious footprints of contamination and that they were too quick to dismiss our concerns as a mere "ex post conjecture.” (ILS, p. 32) Misconceptions are evident in the substantial number of irrational valuations reported by subjects. Furthermore, misconceptions about random devices appear to cause a shifting in subject beliefs about lottery

\footnotetext{
${ }^{1}$ We draw the reader's attention to two important details related to what has been established.

(i) EET is an application of more general theories (prospect theory and reference dependence theory) crafted to explain a specific, experimentally defined phenomenon dealing with commodities. According to the theoretical literature at the time, EET applies only if the reference point is some sure amount, as ILS note (ILS, fn. 5). The literature of the time can be interpreted as claiming that EET makes no prediction when the reference point is set by a lottery. Although KKT (1990, p. 1343) briefly mention "risky prospects" in their discussion section, Tversky and Kahneman (1991), which KKT cite as a foundational model of loss aversion, state that their theory applies to riskless choice. After we produced our results, others developed theories that might be applied to explain gaps in lottery environments (Sugden (2003); Koszegi and Rabin (2006)). Our experiments, however, were not designed to test these alternative theories, which were not available at the time we were writing, nor do our experiments test theories of decision processes such as found in Gigerenzer and Todd (2008).

(ii) We identified a set of procedures that remove gaps in the specific mug experiments cited in the literature as direct confirmations of EET, but there may well be other procedures that remove gaps or influence their existence.
} 
outcomes that is correlated with selling (WTA) and buying (WTP) roles. This suggests that subjects perceive the lottery for which WTA is elicited as different from the lottery for which WTP is elicited. This phenomenon can be interpreted as a failure to measure a gap arising from the valuation of the "same good," the only type of gap of interest for testing EET, which depends on the shape of a preference relation.

Third, despite ILS's claim that they "are not concerned with testing any particular theoretical account of WTP-WTA gaps," (ILS, p. 10) they take up a number of explanations in their conclusion section. In Section 4, we discuss the two most prominent alternative conjectures ILS offer to explain our mug data. The first — the house money conjecture - cannot be tested properly using ILS's data and is inconsistent with patterns of data found in the literature. The second ILS theory is grounded in the impact of procedures, including emphasis on the role of buying and selling and placement of the good, and focuses on how such procedures produce perceptions of loss. This theory is problematic because the observations do not rule out enhancement effects.

Section 5 offers concluding remarks and makes clear that our analysis of the lottery data is consistent with our observations related to the nature of different goods (PZ, 2005, p. 531).

\section{We did not claim that our procedures will eliminate gaps in all contexts and that gaps were eliminated in lottery rounds}

The main claim of PZ (2005) is that the mug experiments that are widely advertized as supporting endowment effect theory do not support it. When procedures are implemented to control for subject misconceptions about the elicitation device, no WTA-WTP gap is observed, contrary to the prediction of EET. ILS interpret our paper as having made additional claims, but the text of our paper and our data supplement, which we sent to ILS upon request early on, ${ }^{2}$ both make clear that these additional claims cannot be attributed to us. The supplement clearly stated that we observed gaps in the lottery data. In addition, it, together with the text of our paper, identified footprints of misconceptions, which we can see now provide the key to a deeper understanding of what the lottery data can teach us about valuation elicitation.

\footnotetext{
${ }^{2}$ The data supplement includes all lottery data and an explanation of the problems we discovered when we analyzed them. We summarized the problems in the 2005 paper.
} 
ILS's statement of their perceived problem with our study mischaracterizes the nature of our procedures. In their abstract, they assert “...other data from the same study, not published in that paper, exhibit a significant and persistent disparity when the same experimental procedures are applied to lotteries." This statement is inaccurate in a major (albeit subtle) way. The lottery data, in fact, were not produced using "the same experimental procedures." These data were produced during practice sessions implemented to remove misconceptions about the elicitation device used to elicit mug valuations, which eventually would be used to test EET. Our procedures call for substantial paid practice prior to collecting data for analysis and testing purposes. The lottery rounds were not preceded by practice.

In this Section, we clarify three important points in an effort to alleviate ILS's concern that readers will (and have) misinterpreted our conclusions, and, most importantly, to make sure readers understand what is learned from PZ (2005). First, readers of the full text of PZ will find that we did not claim the procedures are sufficient to control for misconceptions related to lotteries. Second, readers cannot reasonably conclude that we looked for but found no gaps in the lottery data.

a. PZ (2005) do not claim that the procedures remove all gaps.

ILS state that PZ (2005) "has been widely cited as providing experimental support for the hypothesis that the PZ elicitation procedure eliminates WTP-WTA disparities in general." This claim rests on two sentences in our abstract, which might mislead the reader if read in isolation. The sentences in the PZ abstract read, "Experiments were conducted using both lotteries and mugs, goods frequently used in endowment effect experiments. Using the modified procedures, we observe no gap between WTA and WTP." The abstract should have read, "Experiments were conducted using lotteries as training tools. Endowment effect theory was tested using mugs, goods traditionally used for the development and testing of endowment effect theory."

When PZ is taken as a whole, it is clear we did not claim that the procedures are sufficient to control for misconceptions in all contexts. In fact, we went to great lengths to caution against such a broad interpretation of our results. In several other parts of the paper, we explicitly state that we make no claims about having discovered a set of procedures that remove all sources of misconceptions (e.g., “...we have neither a general theory of what might constitute 
misconceptions nor a set of operational definitions characterizing them. Constructing a full set of procedures to control for them could be very difficult.” (p. 543); “...the concept of misconceptions has not been operationalized formally and certainly not quantified. In fact, its meaning changes from one experimental environment to another, and from experimental study to experimental study. Consequently, a theory of misconceptions has not been developed." (p. 531). We included these statements in the paper specifically to ensure that readers would not interpret claims made about the procedures too broadly. As a general matter, we encourage readers to develop impressions based on our full text. ${ }^{3}$

b. PZ (2005) did not claim that gaps were eliminated in lottery rounds.

While ILS assert that readers of PZ (2005) believe that we looked for and found no gaps in the lottery data, a closer look demonstrates that readers who read parts of the paper not quoted by ILS along with ILS's quotes are very unlikely to draw such a conclusion. While ILS focus on the text in our Abstract and a sentence from our concluding section to claim that readers will interpret us as claiming that we eliminated gaps in the lottery rounds (ILS, p. 5), in other parts of the paper that focus on the results themselves, we make it clear that we did not include the lottery rounds in our analysis. Our footnote 15 states that the lottery data collected during training rounds were not used (and should not be used) to test EET. We described features of the data suggesting that they should not be used to test EET and would be a challenge to any preferencebased theory.

Finally, the studies referenced by ILS as examples of misinterpretations seem not to misinterpret our claims, contrary to ILS's suggestions. None of the quotes mention lottery rounds and some explicitly mention mug rounds. The quotes simply summarize our claim that observed gaps cannot be used to support EET and the data suggest misconceptions are key.

\footnotetext{
${ }^{3}$ As a warning to ILS readers, we note here that ILS sometimes quote from context, omitting key qualifying phrases. For example, while attempting to establish that we made broad claims about the removal of gaps in general, ILS (p. 3) include only part of the following quote: "The 'primary conclusion' they derive from the data they report is that "observed WTP-WTA gaps do not reflect a fundamental feature of human preferences. That is, endowment effect theory does not seem to explain observed gaps." ([PZ,] p. 542). ILS omit the last italicized sentence thereby substantially changing the meaning of our text. This sentence, along with many other statements in our paper, make it clear that we properly focus on experiments using commodities that allow for clean tests of EET. The full quote clearly indicates that we made no claim about all WTP-WTA gaps in all circumstances and unrelated to EET tests.
} 


\section{ILS's mug data reject endowment effect theory}

Before we address ILS's main concern, it is important to remind the reader about our study's major claims and purposes and to emphasize that ILS's mug round data unambiguously reject EET. While ILS claim not to be concerned with explaining observed gaps ${ }^{4}$ (or at least with testing EET ${ }^{5}$ ), the purpose of our study clearly is to test EET. ${ }^{6}$ We find that gaps observed in Kahneman, Knetsch, and Thaler's (KKT) (1990) mug experiments are not due to a kink at the endowment as posited by EET. When the experiment is controlled for subject misconceptions about the elicitation device the valuation gap disappears. ILS conduct experiments with mugs using our procedures. Their mug data confirm our basic conclusion.

Our study was designed specifically to focus on particular experiments developed to demonstrate EET at work - the case of mug experiments, where all alternative explanations seem to be ruled out. Data from both PZ and ILS demonstrate that experiments advanced in the literature as support for EET, i.e. experiments asking subjects to state valuations for goods such as candy and mugs, fail to produce gaps when controls designed to address misconceptions about the elicitation device are implemented. Thus, ILS contribute to the literature by replicating (using modified procedures) the key $\mathrm{PZ}$ result, adding to the data from other experiments that challenge EET as it was originally developed and applied.

ILS avoid a discussion of the relationship between their data and EET by claiming that "PZ do not set out EET as a specific formal theory." (ILS, p. 7) They argue "[a]s used by PZ, 'EET' appears to refer to a loosely-related family of theories of reference-dependent preferences which has evolved and diverged over time..." (ILS, p. 7), concluding that it is impossible to determine whether data support or reject the theory. They justify their avoidance of the issue by arguing that "[s]ince EET is not a sharply-defined concept, engagement with those issues would be an unhelpful distraction from the point of our paper." (ILS, p. 7)

\footnotetext{
4 “[W]e are not concerned with testing any particular theoretical account of WTP-WTA gaps.” (ILS, p. 10)

5 “[W]e are not concerned with PZ's interpretation of what they call EET. Nor are we concerned with whether PZ's or our own data are consistent with EET." (ILS, p. 9-10) Although later in the paper, ILS design experiments to test a house money effect explanation and other explanations for gaps in mug rounds.

${ }^{6}$ We clearly state in our title, abstract and throughout the paper that our experiment is designed specifically to test EET.
} 
This characterization of EET and our study is inaccurate. Contrary to ILS's claim, EET is a precisely stated theory with unambiguous predictions that apply generally. ${ }^{7}$ KKT $(2008$, Fig. 2) provide a clear formulation of EET derived directly from Tversky and Kahneman (1991). The figure displays an indifference curve with a kink at the endowment, indicating that the marginal valuation for a reduction of the quantity of a good exceeds the marginal valuation for an increase in the good. In other words, the prediction that WTA exceeds WTP is deduced directly from Tversky and Kahneman's (1991, pp. 1046-7) axioms. ${ }^{8}$ While ILS claim that EET generates no unambiguous predictions, ${ }^{9}$ the developers and appliers of the theory harbor no such hesitations. For example, Knetsch et al. (2001, p. 257) conclude, "The endowment effect and loss aversion have been among the most robust findings of the psychology of decision making. People commonly value losses much more than commensurate gains independent of transactions costs, income effects or wealth constraints." KKT (1990, p. 1345) also express confidence in the reliability with which the theory can be applied, holding that its consequences can be observed in property rights acquired by historic accident or fortuitous circumstances, government licenses, landing rights, transferable pollution permits, divisions, plants, product lines, etc. Those applying EET in legal contexts have made similar claims. ${ }^{10}$

EET has been applied widely in economics and other fields, and gaps observed in the laboratory are used as evidence of the reliability of the theory as it is applied in the field. The applications assume that a kink exists at the endowment as opposed to other contextual reference points. Our

\footnotetext{
${ }^{7}$ Our paper refers to two of many specific descriptions of the purported link between valuation gaps and prospect theory (PZ, p. 531).

${ }^{8}$ Note that EET is a theory of preferences as opposed to a theory of a decision process as developed by Gigerenzer and Todd (2008) or a hybrid of preference and process as postulated by the discovered preference hypothesis (Plott, 1996). When describing the experiments with mugs, KKT are clear that the shape of the indifference curves and the role of the endowment are important features of the theory: "To conclude, the evidence reported here offers no support for the contention that observations of loss aversion and the consequential evaluation disparities are artifacts; nor should they be interpreted as mistakes likely to be eliminated by experience, training, or 'market discipline.' Instead, the findings support an alternative view of endowment effects and loss aversion as fundamental characteristics of preferences." (KKT, 1990, p. 1346).

${ }^{9}$ KKT (1990) do mention some contexts in which EET might not predict a gap, e.g., goods held for resale and induced-value tokens, but none of these contexts are relevant for our mug experiment.

10 "Researchers in behavioral decision theory have developed a growing line of evidence that people appear to value a good that they own much more than an identical good that they do not own.... Researchers have used several different procedures to demonstrate the endowment effect." (Rachlinski and Jourden, 1998) Rachlinski and Jourden go on to argue that endowment effect theory explains why litigants expend resources to appeal judicial decisions that strip them of property rights even in cases in which the court awards damages to compensate for the loss. Similarly, Huang (2004) suggests that valuation disparities impact settlement behavior of litigants. Law reviews house hundreds of similar applications of endowment effect theory to law.
} 
experiment design was meant specifically to test whether the laboratory evidence conventionally used to support EET (i.e., mug experiments) would hold up when misconceptions about the elicitation device were controlled. Our data, ILS's data and others' data reject EET when put to that test.

\section{Lottery data contamination}

The purpose of our lottery rounds was to provide our subjects with paid practice to help them understand the properties of the Becker-DeGroot-Marschak (BDM) (1964) mechanism and the meaning of and consequences of expressing bids and asks in the BDM context. ${ }^{11}$ During the practice rounds, we elicited valuations for four certainty lotteries in which the outcome was a small amount of money for certain, ${ }^{12}$ in addition to two small stakes, non-certainty lotteries and eight larger stakes, non-certainty lotteries, the outcomes of which were determined randomly. While we were curious whether the training rounds produced useful data, even though they were preceded by no training, our analysis of the data revealed patterns that suggest an appropriate experimental design and control were so lacking that we had no hope of being able to include a convincing analysis of the data.

ILS attempt to develop a set of experimental procedures that removed "all contamination" from lottery choices that we identified in our paper. Indeed, ILS define as their major purpose to determine whether a WTP-WTA gap remains in the lottery rounds after controlling for all sources of contamination. ${ }^{13}$ They describe their experiment as an "uncontaminated replication of PZ's experiment" (ILS, p. 10). In our view, however, it does not control for contamination that we identified and discussed. ILS rejected our analysis of misconceptions as ad hoc theorizing. Unfortunately they did not check their data for the footprints we identified, and it turns out that

\footnotetext{
${ }^{11}$ Given the role of the training rounds, lotteries appealed to us. Using lotteries for training was more efficient than consumer goods because we did not have to have a large number of different commodities on hand for each training decision of each session.

${ }^{12}$ Given ILS's inferences from a paragraph taken from our instructions ("This passage seems to be advising subjects to use the small stakes lottery tasks as practices for the large stakes lottery tasks and possibly (in the case of Treatments 1 and 3) also for the mug task..." (ILS, p. 15), we worry that readers will make the unsupported assumption that we concluded that the four degenerate and two other small stakes lottery rounds were sufficient for training. ILS's interpretation does not reflect our intentions. Our goal was simply to motivate subjects to pay attention during the small stakes rounds.

13 "In mounting our study, our primary objective was to apply PZ's elicitation procedure to both mugs and lotteries while ensuring that none of the paid tasks was contaminated." (ILS, p. 7)
} 
the ILS experiments contain the same evidence of contamination that we identified in our lottery data.

Relative to our concept of what constitutes lottery data contamination, ILS use a narrower definition. ILS use the term "contamination" to describe specific procedures related to the order of the lottery rounds and the personal communications between subjects and the experimenter during the practice rounds. ${ }^{14}$ By contrast, our footnote 15 develops the foundation for our analysis — "The lottery round data... are contaminated by a design that was developed only for training and not for purposes of measuring a gap." Our paper attempts to make clear that we designed the lottery rounds with the single purpose of providing subjects with paid practice with the elicitation device that would subsequently be used to elicit mug valuations to test EET. We neglected all other aspects of training necessary for subjects to understand lotteries. Indeed, for the lottery rounds we made no attempt to apply the revealed theory method, which was central to our paper. ${ }^{15}$

Our footnote 15 continues with a list of both sources and hints of subject misconceptions related to the elicitation device, the nature of randomization and the concept of probability, all of which bear on lottery valuations. The list summarizes the misconceptions analysis contained in a data supplement that we made available to everyone interested in the lottery data, including ILS. When we conducted our study, our view was that the data were not useful for testing EET and possibly not useful for testing any other theory of preference; thus, encouraged by the editor to save space, we saw no need to mention the lottery data analysis in our paper beyond the brief summary that we included. Of course, ILS are correct in assuming that if one wishes to study lottery valuations then special effort must be made to examine subject-experimenter interactions, otherwise one cannot be sure exactly what experiment was conducted. Contamination, however, is a much broader concept than ILS assume. Looking over our lottery data again, together with ILS's data, brings the problems we detected and reported into clearer focus.

\footnotetext{
14 "All WTA rounds were conducted prior to the WTP rounds," and "Mistake corrections, public answers to questions and other procedures were also employed continuously..." (PZ, 2005, fn. 15) ILS interpret our footnote 15 to mean that if these two sources of contamination are properly controlled (or otherwise explained away), the lottery data will be useful for determining whether gaps are linked to misconceptions.

${ }^{15}$ A first cut at applying revealed theory methodology to lottery rounds can be found here in Appendix 1.
} 
Our data supplement reports gaps in the lottery data. It also reveals footprints of misconceptions about random devices that we identified by analyzing the lottery data in light of subject debriefs that provided hints about where to look. More specifically, we reported evidence of irrational valuations, evidence that subjects' subjective probabilities might be influenced by the valuation measurement and inexplicable risk preference patterns. We find the same footprints of misconceptions in the ILS lottery data, and closer study reveals patterns in the data that challenge ILS's enterprise of using lottery valuations to measure WTP-WTA gaps.

While we presented no general theory of misconceptions, the existence of footprints of misconceptions about the random device implies that misconceptions cannot be ruled out as an explanation of patterns observed in the lottery data. In the remainder of this Section, we provide a preliminary analysis of our conjectures related to the lottery data. The data suggest that our training procedures are inappropriate for eliciting lottery valuations. These are the footprints of contamination that our footnote 15 and data supplement report.

\section{a. Irrational Choices.}

The natural places to look for evidence of misconceptions are those in which the indicators are uncontroversial and clear. For this reason, we first examine subject valuations of the four lotteries with certain payoffs. Under the BDM procedure, the dominant strategy is to value certainty lotteries at the certain value. Presumably, any irrational choices expressed in these lotteries reflect misconceptions, misunderstanding or confusion on the part of the subjects.

A close look at ILS's lottery data reveals substantial irrationality, both in general and relative to our lottery data. As ILS explain, their subjects' and fixed offers were restricted to multiples of £ .05 . Thus, the only rational valuations for a lottery with a certain payoff of $X$ are $X$ and $X+.05$ for sellers (WTA) and X and X - .05 for buyers (WTP). Table 1 reports the proportion of irrational valuations reported by ILS's subjects and our subjects for the four lotteries with certain outcomes. For example, in Lottery \#1, 28\% of ILS's subjects failed to state a rational value for a lottery that paid 20 pence with certainty. On average, in each certainty lottery round, roughly $23 \%$ of ILS's subjects exhibited irrationality in this seemingly simple task. The irrationality displayed by ILS's subjects is approximately seven times higher than that displayed by our subjects; roughly $3.4 \%$ of our subjects' valuations, on average per round, were irrational. ILS 
suggest that their modifications of our procedures removed all contamination, but their data demonstrate that they did not.

\begin{tabular}{|c|c|c|c|c|}
\hline \multicolumn{5}{|c|}{ Table 1: FREQUENCY OF IRRATIONAL VALUATIONS FOR CERTAINTY LOTTERIES } \\
\hline & Lottery \#1 & Lottery $\# 2$ & Lottery $\# 4$ & Lottery \#5 \\
\hline Certain payoff & 20 cents/pence & 30 cents/pence & 30 cents/pence & 40 cents/pence \\
\hline ILS & $28 \%$ & $24 \%$ & $19 \%$ & $22 \%$ \\
\hline PZ & $3 \%$ & $3 \%$ & $3 \%$ & $5 \%$ \\
\hline
\end{tabular}

The difference between ILS's and our data is striking, and we can only speculate about the reasons. As we explained in our paper, we detected what appeared to us to be a substantial lack of understanding of BDM during the early training rounds and used hands-on methods to correct it. ILS, following our footnote, viewed the hands on procedures as a possible source of contamination from an experiment design perspective and employed computerized instructions that involved different methods. The levels of irrational behavior exhibited in ILS's data, however, suggest that either our training procedures did at least some work to reduce some misconceptions or the procedures they used generated additional misconceptions.

Irrational valuations of non-certainty lotteries are similarly signaled by valuations that fall outside the support of a lottery value's probability distribution (when payoffs are positive). If a lottery has a zero probability of paying more than $\mathrm{x}$ and a zero probability of paying less than $\mathrm{y}$, then valuations above $\mathrm{x}$ or below $\mathrm{y}$ violate rationality postulates. The ILS non-certainty lottery data exhibit very little irrationality according to this definition, and thus stand in sharp contrast to their certainty lottery data discussed above. Indeed, the change in behavior between certainty and non-certainty lotteries is dramatic. On average, in the non- certainty lottery rounds, $3.6 \%$ of ILS's subjects reported irrational valuations, as defined in the subsection above, whereas $22 \%$ exhibited irrational behavior in lottery \#5, the last certainty lottery round. While further investigation is required to determine the factors driving this phenomenon, the sudden change in behavior - substantial irrationality in a simple task to almost no irrationality in a more complex task - is another footprint of misconceptions. In the following section, we provide a more detailed examination of the nature of the misconceptions suggested by both sets of data 


\section{b. Boundary Valuations.}

All ILS and PZ lotteries take the same form. Each results in a payout of $\mathrm{x}$ with probability $\mathrm{P}(\mathrm{x})$ and a payout of $y$ with probability $1-\mathrm{P}(\mathrm{x})$. The preference elicitation procedures are designed to elicit the subject's lottery value, V. Under such conditions, standard models of risky choice, including the model ILS adopt (p. 13), hold that $\mathrm{V}=\mathrm{x}$ if and only if $\mathrm{P}(\mathrm{x})=1$, and $\mathrm{V}=\mathrm{y}$ if and only if $\mathrm{P}(\mathrm{x})=0$. This property is true regardless of the level of risk aversion. ${ }^{16}$ Thus a valuation at the boundary of a lottery payoff support suggests an extreme belief over the outcome probabilities. Of course, this model assumes that possible lottery outcomes are continuous and that utility functions are smooth, if the mathematical properties are viewed only as approximations, boundary valuations imply beliefs that are inconsistent with the objective probabilities of the lottery value supports. In other words, under such simplifying assumptions, the existence of boundary valuations is evidence that subjects have misconceptions about randomness. We hasten to add that an individual choice model assuming a kink in the preference relation at a possible reference point might be consistent with the lottery data (although in some cases, it might require extreme levels of loss aversion). Thus, the discussion of this section must be considered as tentative conjectures.

To investigate footprints of misconceptions in the non-certainty large stakes lottery rounds, we focus on "boundary valuations." We define boundary valuations as valuations that lie exactly on the bounds of the support or irrationally outside the bounds. For example, ILS lottery \#13 (a buying task) paid $£ 3.5$ with probability 0.5 and $£ 1.5$ with probability 0.5 ; thus, all valuations at $£ 3.5$ or above are counted as "at or above the upper bound of the value support," and in this case $5(5 \%)$ of ILS's subjects reported such valuations. All valuations at $£ 1.5$ or below are counted as "at or below the lower bound of the value support," and in this case 15 (15\%) of ILS's subjects reported such valuations. Even though valuations exactly on the bounds are not strictly irrational as defined in the previous subsection, these valuations are sufficiently extreme to challenge reasonable assumptions related to belief formation. Table 2 displays the frequencies of boundary valuations for large-stakes, non-certainty lotteries. In both experiments, subjects valued large stakes lotteries as sellers (WTA) in rounds 7-10 and as buyers (WTP) in rounds 11-14.

\footnotetext{
${ }^{16}$ ILS reference constant absolute risk aversion as a measure of attitudes toward risk. (ILS, p. 13)
} 
Several features of the data are instructive. First, ILS subjects more frequently reported boundary valuations. On average each round, $13.4 \%$ of ILS's subjects reported boundary valuations; 8.2\% of our subjects, on average across rounds, reported such valuations (counting only lotteries with non-negative outcomes - lotteries \#9 and \#13 had a negative lower bound in our experiment).

While the ILS boundary valuations are more frequent than ours, both are suspiciously large. Given the experimental environment, these subjects do not exhibit sophisticated beliefs over lottery outcomes and are acting as if they know the lottery outcome with certainty, a phenomenon that we reported in our paper and in the data supplement.

c. "Boundary Valuation Asymmetries" and a "Question-Influenced Beliefs Conjecture". A closer look at Table 2 reveals that subject beliefs appear to be directly influenced by whether they are asked to state their WTA or WTP. That is, the boundary valuations suggest a tendency for these subjects to believe that the high payoff will occur with certainty when they are asked for a selling price (WTA) and that the low payoff will occur with certainty when they are asked how much they would pay (WTP). We reported this phenomenon in our data supplement but considered it evidence only of contamination as opposed to a phenomenon that might be worthy of independent study. A quick search through the literature reveals that others have reported closely related phenomena elsewhere (e.g., Risen and Gilovich, 2007).

\begin{tabular}{|c|c|c|c|c|}
\hline \multicolumn{5}{|c|}{$\begin{array}{c}\text { TABLE } 2 \\
\text { BOUNDARY VALUATIONS FOR UNCERTAIN LARGE STAKE LOTTERIES } \\
\text { ILS N=400 (100 subjects, each valuing four lotteries); PZ N=222 (74 subjects, each valuing three } \\
\text { lotteries) }\end{array}$} \\
\hline & \multicolumn{2}{|c|}{ ILS } & \multicolumn{2}{|c|}{$\mathbf{P Z}$} \\
\hline & $\begin{array}{l}\text { WTA Boundary } \\
\text { Valuations } \\
\text { Lotteries } \\
7,8,9,10\end{array}$ & $\begin{array}{l}\text { WTP Boundary } \\
\text { Valuations } \\
\text { Lotteries } \\
11,12,13,14\end{array}$ & $\begin{array}{l}\text { WTA Boundary } \\
\text { Valuations } \\
\text { Lotteries } \\
7,810^{*}\end{array}$ & $\begin{array}{l}\text { WTP Boundary } \\
\text { Valuations } \\
\text { Lotteries } \\
11,12,14^{*}\end{array}$ \\
\hline $\begin{array}{c}\text { Valuations at or above } \\
\text { the upper bound of the } \\
\text { value support }\end{array}$ & $7.3 \%(29)$ & $3.8 \%(15)$ & $7.7 \%(17)$ & $3.2 \%(7)$ \\
\hline $\begin{array}{l}\text { Valuations at or below } \\
\text { the lower bound of the } \\
\text { value support }\end{array}$ & $1.8 \%(7)$ & $14.0 \%(56)$ & $0.9 \%(2)$ & $5.0 \%(11)$ \\
\hline
\end{tabular}


A "boundary valuation asymmetry" or, more generally, the support for a question-influenced beliefs conjecture appears as the asymmetric tendency for subjects to be more likely to report boundary valuations at or above the upper bound in selling (WTA) rounds and at or below the lower bound in buying (WTP) rounds. For example, when asked to report WTA, 7.3\% of ILS's subjects reported a value at or above the upper bound while $1.8 \%$ of their subjects choose at or below the lower bound, a ratio of just over 4 to 1 . When their subjects were asked to report WTP, however, the ratio of upper to lower bound choices reverses to roughly 1 to 4 (3.8\% v. $14.0 \%)$. Our subjects exhibited the same tendency: for WTA, the ratio of upper to lower bound values was 8.5 to 1 , and for WTP it fell to 1 to $1.6 .^{17}$

Simply put, the data support a question-influenced beliefs conjecture. Specifically, the conjecture holds that when reporting valuations as sellers, subjects are more likely to believe that the lottery outcome will be the higher payoff. Conversely, when subjects report valuations as buyers, they are more likely to believe that the lottery outcome will be the lower payoff.

The question-influenced beliefs conjecture has implications for the issues of interest to ILS. It implies that observed WTP-WTA gaps might be due to a difference in the beliefs about outcomes that is influenced by the preference elicitation question. This suggests that observed gaps could be due to an uncontrolled, systematic shifting of beliefs as opposed to the shape of the preference relation EET assumes. The conjecture also has implications for the use of lotteries in the measurement of WTP-WTA gaps. If misconceptions about the random device cannot be controlled, and in particular, if the systematic violation of sophisticated beliefs cannot be avoided, then there is an issue about the use of lotteries to measure WTP-WTA gaps, which assume that individuals value the same good as buyer and seller. If the roles of seller and buyer trigger a change in subjective probabilities for the same lottery, then from the subject's point of view the lottery valued from the buying perspective is not the same as the lottery valued from the selling perspective. Unless subjects view the good as the same good from both perspectives, or

\footnotetext{
${ }^{17}$ Proportion of at or above the upper bound valuations in ILS's WTA rounds (7.3\%) exceeded the proportion of at or above the upper bound valuations in ILS's WTP rounds $(3.8 \%)(\mathrm{p}=0.02$; one-tailed test). Similarly, $14 \%>1.8$ $\%(\mathrm{p}=0.00) ; 7.7 \%>3.2 \%(\mathrm{p}=0.02) ;$ and $5 \%>0.9 \%(\mathrm{p}=0.005)$. Using proportions from each round, we also conducted one-tailed tests of equal proportions to test whether subjects are more likely to report valuations at or above the upper bound in WTA rounds relative to WTP rounds. Five of the eight tests using ILS's data resulted in a statistically significant difference (at the $5 \%$ level); four of the six tests using our data produced similar results.
} 
unless the standard theory can be adjusted to deal with this phenomenon, testing EET or even measuring a valuation gap using lotteries becomes difficult if not impossible.

We note that the analysis offered here is focused on the boundary choices, the only cases in which beliefs can be clearly measured and separated from preferences. In Appendix 1, we provide additional statistics related to the sensitivity of the WTP-WTA gap to the removal of the boundary values. ${ }^{18}$ Our conjecture is that the overall gap is influenced by the small set of valuations on or outside the boundaries. We include in the appendix some insights about the literature related to controlling beliefs and the set of procedures a thorough application of revealed theory methodology might produce. Our hope is that the methods suggested by the literature will provide tools for removing the unwanted influences we detected in the lottery data, which discouraged us from using it to test theories such as EET.

\section{d. Preference Consistency and Risk Preferences.}

In footnote 15, we suggested problems related to subjects' ability to assign values to lotteries. In our data supplement, we were more explicit about the usefulness of the lottery data for testing theories such as EET. The footprints of misconceptions we reported included an analysis of risk preferences. Classical prospect theory holds that individual preferences are possibly risk averse in the gains and possibly risk seeking in the losses. (Kahneman and Tversky, 1979) Individuals, however, are postulated to have consistent (complete and transitive) risk preferences given an endowment (or reference point). That is, risk preferences will change as the endowment changes, but, given the endowment, risk preferences are of a classical type. Even neglecting the possibility that EET does not apply to lotteries, testing with data that violate these fundamental assumptions seems unhelpful.

The problem we saw in our data, and that we see in ILS's data, is that subjects appear to exhibit shifting preferences and shifting risk attitudes as expectations and experience evolves. While modern theory might be able to accommodate such instability, it presents a challenge to EET as it is traditionally developed and applied. Both ILS's and our subjects failed to exhibit stable risk preferences across rounds. For example, only $38 \%$ of ILS subjects consistently displayed risk aversion in all of the large stakes buying rounds. Similarly, only $23 \%$ of our subjects consistently

\footnotetext{
${ }^{18}$ The analysis is included here as Appendix 1.
} 
bid below the expected value of the lottery in every large stakes buying round. ${ }^{19}$ While such proportions suggest that a large number of subjects had risk seeking preferences, very few subjects consistently bid the expected value or bid above the expected value in all of the large stakes buying rounds. ${ }^{20}$ Thus, $53 \%$ of ILS's subjects and $64 \%$ of our subjects failed to exhibit consistent risk preferences in buying rounds. Such instability, the flopping back and forth between risk aversion and risk seeking behavior in WTP rounds, suggests a loss of experimental control and suggests that, without insights about the nature of the randomness, the data are of questionable value for gap measurement and for theory testing. The same instability is observed in selling rounds, with $70 \%$ of ILS's subjects and $72 \%$ of our subjects exhibiting inconsistent risk preference throughout those rounds. ${ }^{21}$ A natural hypothesis is that this general pattern of instability is related to the question-influenced beliefs conjecture, but we mention it only to bring the possibility to the reader's attention since it is beyond the scope of this paper.

In conclusion, it is important to remember that EET rests on a theory of preferences characterized by a specific kink at the reference point set by the endowment. Thus, if EET is tested using any data for which the reference point is known or assumed to be known, and if the data fail to exhibit consistent preferences, the theory is rejected. The lottery data might tell a useful story if applied to modern extensions of prospect theory, especially those assuming the reference point is set by something other than the endowment. Pointing to the lottery data as either support for or rejection of EET, however, would not be credible given that major features of the data disconfirm the basic assumptions of EET.

\footnotetext{
${ }^{19}$ Risk aversion is commonly reported in experiments, so a lack of evidence of risk aversion (especially in buying rounds as some versions of EET predict risk seeking behavior in selling rounds) signals a possible lack of experimental control. Of 400 large stakes WTP valuations in ILS's study, $91(23 \%)$ were above expected value. The results are starker if we include the small stakes lotteries. In PZ's study, 63 (21\%) of 296 large stakes WTP valuations were above expected value. This calls control into question in both experiments.

${ }^{20}$ Three percent (8\%) of ILS (PZ) large stakes lottery buyers bid the expected value each round. Six percent (5\%) consistently bid above expected value in these buying rounds.

${ }^{21}$ Eleven percent (5\%) of ILS (PZ) large stakes lottery owners offered below expected value each round. Thirteen percent $(11 \%)$ consistently offered above expected value in these rounds. Six percent (12\%) consistently offered the expected value in these rounds.
} 


\section{Explanations for gaps: House money effect, enhancement effect theory and endowment effect theory.}

Despite ILS's claim that they are "not concerned with testing any particular theoretical account of WTP-WTA gaps" (ILS, p. 10), they include expansive discussions of possible explanations. Specifically, they offer two conjectures to explain the mug results reported both by us and by them. Both conjectures are problematic. We discuss them in turn and note that their second theory is simply a version of a more general theory we call enhancement effect theory, which holds that the process of acquisition and experience of ownership can create special features of goods that have independent value that can be confused with a kinked preference relation.

\section{a. The House Money Effect.}

The first conjecture is that the elimination of the gap in mug rounds is due to a house money effect triggered not by cash from lottery winnings but by the show up fee paid in cash at the beginning of the experiment. While this alternative explanation is worth considering, we note that it does not work to explain the broader set of results found in the literature. It also provides additional evidence to reject EET. ${ }^{22}$

While ILS's results are suggestive, one should be hesitant to accept the house money effect explanation on the basis of this limited evidence. While ILS prefer not to formally test the conjecture, it could be tested in many ways, the most straightforward of which would be to replicate KKT's gap result and then add a show up fee to the KKT procedures. The disappearance of the gap would serve as evidence of the house money effect conjecture. ILS, however, cannot perform this test because they have not produced a baseline using KKT's original procedures, which do not include a show up fee but result in a gap. They claim that they performed a "controlled comparison between the PZ and KKT elicitation procedures," (ILS, p. 27) but they have not. Since ILS do not perform this experiment, the lack of a gap in their modified KKT experiment possibly is a result of a different subject pool or subtle differences between KKT's original procedures and ILS's modification of them. That is, it could be the case

\footnotetext{
${ }^{22}$ Of course, others might argue that, rather than rejecting EET, the evidence simply suggests that multiple effects exist and, in some cases, one effect will dominate the others. If this were the case, however, EET would need to be modified to take these other effects into account. This adaptation of the theory, however, would seriously compromise the effect's robustness and would call into question the myriad applications of EET. See Zeiler (2010) for numerous examples of applications in law.
} 
that KKT's results simply are not robust to slight changes in procedures, which would imply that EET does not explain gaps.

Second, their explanation does not work well to explain the pattern of results reported in the literature. Experiments conducted by Kovalchik et al. (2005) employ the PZ procedures and do not observe a gap in mug valuations, yet they do not employ a show up fee. This result is contrary to the predictions of the ILS conjecture that PZ's elimination of the gap is the result of a house money effect. In addition, the experiments performed by Smith (2008) employ KKT's procedures but add a show up fee. Contrary to the prediction of ILS's theory, Smith reports a valuation gap. Thus the broader literature meets the ILS house money effect explanation of our mug gap with skepticism.

\section{b. Enhancement Effect Theory.}

The second theory ILS advance to explain gaps observed in the lab is based on a blurring of EET with what we call "enhancement effect theory." Enhancements are generated through the process of endowment or the experience of ownership. Enhancements create value that is added to value that exists in the absence of the enhancement. ${ }^{23}$ For example, if the experimenter announces, "the mug is a gift" when endowing subjects, the nature of the good in the eyes of non-owners and owners might differ. (Plott and Zeiler, 2007) Potential buyers are deciding about a mug, while potential sellers are deciding about a mug that was a gift from someone who will observe whether the "gift" is traded for something else. Sellers who benefit from signaling appreciation to the experimenter might be more likely to ask for more than they would if they were considering only the mug's consumption value.

Examples of valuation gaps taken from the field demonstrate the potential for blurring enhancements and endowments. In the field, ownership is often associated with enhancements that supplement, modify and shape the value of a good for potential sellers. For example, a potential home seller values his home from the perspective of someone who has lived in it for

\footnotetext{
${ }^{23}$ In a separate study, we explore environments in which features of the experiment design generate enhancements that might add value to endowed goods. (Plott and Zeiler, 2007) Specifically, we tested what we now call enhancement effect theory against EET and found support for enhancement effect theory. While we focused on features that enhance the value of endowments in an effort to explain exchange asymmetries, we recognize the possibility that features of the environment might also reduce the value of the endowed good, possibly leading to buyer valuations that exceed seller valuations.
} 
some time. The independent value from enhancements that shape the seller's overall value could emerge from many unobservable sources or could manifest in observable ways, e.g. through the good memories that living there create. Economic theory posits a number of sources of enhancements that might produce gaps, such as value associated with a trophy or the first dollar one earns, or values associated with information asymmetries (e.g., a risk-averse owner might place a higher value on the car she has been driving relative to an identical car that was previously owned by someone else simply because she is more certain about how her car impacts her utility). If we count unobserved beliefs as enhancements and if almost any behavior can be supported by some assumption about beliefs, it becomes difficult to separate EET from enhancement effect theory. Despite this difficulty, the question-influenced beliefs phenomenon we reported in Section III provides at least some opportunity for separation.

Without the ability to control for enhancement effect theory as an alternative explanation, we are unable to determine whether a kink in the preference relation at the reference point is causing gaps observed in complex field environments, or whether ownership (for more than just a few minutes) has somehow changed the nature of the good. It is hard to imagine an example taken from the field and used as support for EET that could not also be explained by some, imagined but unobserved enhancement effect, including beliefs and expectations. ${ }^{24}$ Of course, this calls into question the falsifiability of enhancement effect theory when applied in the field. A similar problem, however, is a challenge to field applications of EET. Essentially any gap in the field also can be attributed to some unobserved reference point combined with loss aversion when in fact some enhancement or some systematically varying belief might be at work.

The problems of distinguishing EET from enhancement effect theory naturally spill into the laboratory. For example, ILS criticize our instructions as biasing the results against EET by using the word "offer" as opposed to words like "buy" and "sell." They assert that such language "reduc[es] the salience of the distinction between buying and selling tasks." (ILS, p. 27) They argue that, while our subjects are told that they own the good, "there is little else to flag up the difference between buying and selling, whereas other experiments draw more attention to this

\footnotetext{
${ }^{24}$ Genesove and Mayer (2001) is an example demonstrating the possibility of separating loss aversion (with the purchase price as the reference point) from enhancement effect theory in a field environment. Enhancement effect theory seems not to explain the results, depending on assumptions made about beliefs. We thank the editor for bringing the example to our attention.
} 
difference.”(ILS, p. 28) Enhancement effect theory predicts, however, that subjects might perceive the experimenter's emphasis of roles as information about the value of the goods (PZ, 2007). Emphasis on "buyer" and "seller" roles can also trigger strategic instincts that cause sellers to offer high amounts and buyers to offer low amounts (PZ, 2005, p. 537-38). Therefore, if we emphasize buying and selling and we observe a gap, we can't be sure whether the result supports EET or enhancement effect theory (or reversion to basic instincts). ${ }^{25}$ Similarly, ILS argue that placement of the good might impact the setting of the reference point, and that elimination of the gap in our experiment might be due to the fact that both sellers and buyers had mugs in front of them. (ILS, p. 28) Again, if we make such a change and observe a gap, enhancement effect theory cannot be ruled out because it suggests that placement of the goods might signal relative value. (PZ, 2007) Given that the theories are observationally equivalent in general settings, separation of them requires highly controlled laboratory settings.

\section{Concluding remarks}

PZ (2005) draws a specific conclusion: EET does not explain the WTP-WTA gap observed in the classic mug experiments that were designed specifically to give the theory its best shot. ILS replicate this result, providing support for our central conclusion.

That EET does not explain gaps does not tell us what does explain them. Our analyses (PZ 2005 and PZ 2007) offer two conjectures, both of which are related to experiment procedures. The first posits that gaps are due to misconceptions related to the elicitation mechanism. The second advances enhancement effect theory as an explanation. Enhancement effect theory holds that gaps arise from enhancements predicted by economic theory and generated by the method of endowment and, perhaps, by the elicitation procedures. While it was not their purpose, ILS's results add to the evidence we present here that lottery gaps are related to misconceptions about randomness and beliefs about probabilities produced by preference elicitation procedures. Thus, the ILS experiments bring into focus a dimension of misconceptions that we posited and that, upon further exploration, have been found to raise questions about the appropriateness of

\footnotetext{
${ }^{25}$ We should add that the forms subjects used to record valuations mentioned buying or selling more than once immediately prior to the elicitation of the offer. For example, the forms used to elicit valuations from buyers read: "Buyer Record Sheet: The experimenter owns one Round X lottery ticket. I will offer to buy the lottery ticket for an amount equal to the maximum I am willing to pay for the ticket." (emphasis added)
} 
interpreting observed lottery gaps as revealing preferences for the same item in the selling role and in the buying role.

PZ (2005) makes clear that we were curious about experimental procedures and associated misconceptions. Our observation related to the nature of goods was (and is) that others have focused on the properties of the endowed good, e.g. the difference between mugs and money or tokens for money, as an explanation for gaps, suggesting that the disparity in gap results that we highlighted in Table 1 in PZ (2005) is caused by the lack of comparability of different properties (Tversky and Kahneman (1991)). The conclusion of PZ (2005) was that the mug experiments do not support theories based on the properties of goods formulated to explain the disparity of results across experiments. The claims we make here about the different nature of lotteries are unrelated to our previous claim. Here we argue that properties of goods, such as the randomness associated with lotteries, might carry an inherent possibility of misconceptions, which might lead to gaps. Indeed, our analysis of ILS's and our lottery data supports the view that misconceptions indeed play a role in producing lottery gaps and that different goods might call for different controls for misconceptions. Just as we argued in PZ (2005), however, a full understanding and appropriate test of our conjecture will require an application of revealed theory methodology, which neither ILS nor we applied. 


\section{References}

Becker, Gordon M.; DeGroot, Morris H. and Marschak, Jacob. 1964. "Measuring Utility by a Single-Response Sequential Method.” Behavioral Science, 9(3):226-32.

Camilleri, Adrian R. and Newell, Ben R. 2009. "The role of representation in experience-based choice." Judgment and Decision Making, 4(7) 518-29.

Genesove, David and Mayer, Christopher. 2001. "Loss Aversion and Seller Behavior: Evidence From the Housing Market.” Quarterly Journal of Economics, 116(4):1233-60.

Gigerenzer, Gerd and Todd, Peter M. 2008. "Rationality the Fast and Frugal Way: Introduction." In Handbook of Experimental Economic Results, ed. Charles R. Plott and Vernon L. Smith, 977-85, North Holland.

Huang, Peter H. 2004. "Lawsuit Abandonment Options in Possibly Frivolous Litigation Games." The Review of Litigation, 23:47-xx.

Isoni, Andrea; Loomes, Graham and Sugden, Robert. 201x. "The Willingness to Pay-Willingness to Accept Gaps, the 'Endowment Effect,' Subject Misconceptions, and Experimental Procedures for Eliciting Valuations: A Reassessment," American Economic Review, forthcoming.

Kahneman, Daniel; Knetsch, Jack L. and Thaler, Richard H. 1990. "Experimental Tests of the Endowment Effect and the Coase Theorem.” Journal of Political Economy, 98(6):132548.

Kahneman, Daniel; Knetsch, Jack L. and Thaler, Richard. 2008. "The Endowment Effect: Evidence of Losses Valued More Than Gains.” In Handbook of Experimental Economic Results, ed. Charles R. Plott and Vernon L. Smith, 939-48, North Holland.

Kahneman, Daniel and Tversky, Amos. 1979. "Prospect Theory: An Analysis of Decision under Risk.” Econometrica, 47(2):263-92.

Knetsch, Jack L.; Tang, Fang-Fang and Thaler, Richard H. 2001. "The Endowment Effect and Repeated Market Trials: Is the Vickrey Auction Demand Revealing?” Experimental Economics, 4:257-69.

Koszegi, Botond and Rabin, Matthew. 2006. "A Model of Reference-Dependent Preferences." Quarterly Journal of Economics, 121(4):1133-65.

Kovalchik, Stephanie; Camerer, Colin F.; Grether, David M.; Plott, Charles R. and Allman, John M. 2005. "Aging and Decision Making: A Comparison Between Neurologically Healthy Elderly and Young Individuals." Journal of Economic Behavior and Organization, 58:79-94.

Plott, Charles R. 1996. "Rational Individual Behavior in Markets and Social Choices Processes: The Discovered Preference Hypothesis." In The Rational Foundations of Economic Behavior, eds. Kenneth J. Arrow, Enrico Colombatto, Mark Perlman and Christian Schmidt, IEA Conference Vol. 114: 225-50. London: Macmillan.

Plott, Charles R. and Zeiler, Kathryn. 2005. "The Willingness to Pay/Willingness to Accept Gap, the 'Endowment Effect,' Subject Misconceptions and Experimental Procedures for Eliciting Valuations." American Economic Review, 95:530-45. 
Plott, Charles R. and Zeiler, Kathryn. 2007. "Exchange Asymmetries Incorrectly Interpreted as Evidence of Endowment Effect Theory and Prospect Theory." American Economic Review, 97(4):1449-66.

Rachlinski, Jeffrey J. and Jourden, Forest. 1998. "Remedies and the Psychology of Ownership." Vanderbilt Law Review, 51:1541-82.

Risen, Jane L. and Gilovich, Thomas. 2007. "Another Look at Why People Are Reluctant to Exchange Lottery Tickets.” Journal of Personality and Social Psychology, 93(1):12-22.

Smith, Alex. 2008. "Lagged Beliefs and Reference Dependent Utility." PhD diss. University of Arizona Department of Economics.

Sugden, Robert. 2003. "Reference-dependent subjective expected utility." Journal of Economic Theory, 111:172-91.

Tversky, Amos and Kahneman, Daniel. 1991. "Loss Aversion in Riskless Choice: A ReferenceDependent Model.” Quarterly Journal of Economics, 106(4):1039-61.

Zeiler, Kathryn. 2010. "Willingness to Pay-Willingness to Accept Gaps: The Legal Implications of Recent Empirical Developments." Unpublished. 


\title{
Appendix One to
}

\section{Endowment Effect Theory, Subject Misconceptions and Enhancement Effect Theory: A Reply to Isoni, Loomes and Sugden}

\author{
Charles R. Plott and Kathryn Zeiler
}

April 15, 2010

This appendix supplements our published Reply in two ways. In Section I, we provide a more detailed study of the lottery data, analyzing the individual lottery valuations as opposed to the aggregates reported in our Reply. The disaggregated data provides additional support for the conjecture that misconceptions about random devices appear to cause a shifting in subject beliefs about lottery outcomes that is correlated with selling (WTA) and buying (WTP) roles, and it assesses the impact of these misconceptions on WTA and WTP measures. While WTA-WTP gaps might be evident in aggregate lottery valuations, the analysis reported here suggests that the "question-influenced beliefs" conjecture is a viable alternative explanation to the theory that the gap reflects a special shape of preference relations. In Section I, we refine this conjecture and offer an analysis of the lottery data that supports it. The combined implication is that the lottery data do not unambiguously support theories developed to extend EET to the case of lotteries.

The key to further investigation and testing seems to be methods of controlling beliefs and correcting misconceptions about random devices and probabilities. In Section II, we discuss some of the diverse literature that provides clues about how to control for such misconceptions. This experimental literature suggests that our procedures are ill-equipped to elicit lottery valuations for the purpose of testing EET (or almost any preference-based theory). We provide the beginnings of an analysis that would be required to generate a set of controls to remove misconceptions related to random devices.

\section{Boundary Valuation Asymmetries}

In Section 3 of our Reply we provided the first steps of an analysis of the footprints of contamination in the lottery data. Section 3a of our Reply reveals substantial irrationality in 
ILS's and our lottery data. Subjects frequently bid outside the bounds of the lottery value support in the certainty lottery rounds $\left(1,2,4\right.$ and 5). ${ }^{1}$ Sections $3 \mathrm{~b}$ and $3 \mathrm{c}$ of our Reply continue with an analysis of the asymmetry in boundary valuations, defined as those valuations that lie exactly on or outside the bounds of the lottery value support. ${ }^{2}$ Most importantly, we reported the presence of boundary valuation asymmetries: the tendency for subjects to value the lottery at or above the lottery value support in WTA rounds and at or below the support in WTP rounds. Table 1 below expands on Table 2 of our Reply and demonstrates that the asymmetry that appears in the aggregate data also appears in most individual lottery rounds.

Given the experimental environment and given appropriate simplifying assumptions about risk preferences, these subjects do not exhibit sophisticated beliefs over lottery outcomes, which represent probability distributions over the state space. Specifically, they are acting as if they can accurately guess the lottery outcome. We reported this phenomenon in our data supplement. We also find it in the data reported by ILS, which demonstrates that their experiment did not remove contamination as we defined the term.

\begin{tabular}{|c|c|c|c|c|c|c|c|c|c|}
\hline \multicolumn{10}{|c|}{$\begin{array}{c}\text { Table } 1: \\
\text { FREQUENCY OF BOUNDARY VALUATIONS FOR UNCERTAIN LARGE-STAKES LOTTERIES }\end{array}$} \\
\hline & & \multicolumn{4}{|c|}{ WTA BOUNDARY VALUATIONS } & \multicolumn{4}{|c|}{ WTP BOUNDARY VALUATIONS } \\
\hline & & $\# 7$ & $\# 8$ & $\# 9$ & $\# 10$ & $\# 11$ & $\# 12$ & $\# 13$ & $\# 14$ \\
\hline \multirow{3}{*}{$\begin{array}{c}\text { ILS } \\
(\mathrm{N}=100)\end{array}$} & $\begin{array}{l}\text { lottery value } \\
\text { support }(£)\end{array}$ & {$[0,3]$} & {$[0,2]$} & {$[0.5,2.5]$} & {$[0,4]$} & {$[1,4]$} & {$[1,3]$} & {$[1.5,3.5]$} & {$[1,5]$} \\
\hline & upper & $14 \%{ }^{* *}$ & $5 \%$ & $5 \%$ & $5 \%$ & $5 \%$ & $2 \%$ & $5 \%$ & $3 \%$ \\
\hline & lower & $0 \%$ & $0 \%$ & $7 \%$ & $0 \%$ & $8 \% * * *$ & $18 \% * * *$ & $15 \% * *$ & $15 \% * * *$ \\
\hline \multirow{3}{*}{$\begin{array}{c}\mathrm{PZ} \\
(\mathrm{N}=74)\end{array}$} & $\begin{array}{l}\text { lottery value } \\
\text { support }(\$)\end{array}$ & {$[0,7]$} & {$[0,5]$} & {$[-4,8]$} & {$[0,10]$} & {$[1,8]$} & {$[1,6]$} & {$[-3,9]$} & {$[1,11]$} \\
\hline & upper & $8 \% * *$ & $7 \% * *$ & $0 \%$ & $8 \%$ & $1 \%$ & $1 \%$ & $0 \%$ & $7 \%$ \\
\hline & lower & $1 \%$ & $0 \%$ & $4 \%$ & $1 \%$ & $7 \% * *$ & $7 \% * *$ & $1 \%$ & $1 \%$ \\
\hline \multicolumn{10}{|c|}{$\begin{array}{l}\text { Note: "Upper" ("lower") indicates the proportion of subjects who valued the non-degenerate lottery at or above (below) the } \\
\text { upper (lower) bound of the lottery value support. The asterisks denote results of tests of equal proportions (* denotes } \\
\text { significance at the } 10 \% \text { level, } * * \text { at the } 5 \% \text { level and } * * * \text { at the } 1 \% \text { level). For upper boundary valuations, Ho: proportion } \\
\text { of valuations at or above upper bound in WTA = proportion of valuations at or above upper bound in WTP; Ha: proportion } \\
\text { at or above upper bound in WTA rounds > proportion at or above upper bound in WTP. For example, } 14 \% \text { at or above the } \\
\text { upper bound in ILS's round } 7 \text { is compared to } 5 \% \text { at or above the upper bound in ILS's round } 11 \text {. Similar tests are performed } \\
\text { on lower boundary valuations (Ho: proportion of valuations at or below lower bound in WTA = proportion of valuations at } \\
\text { or below lower bound in WTP; Ha: proportion at or below lower bound in WTA rounds }<\text { proportion at or below lower } \\
\text { bound in WTP). For lotteries with negative or zero lower bounds, the frequency represents offers of } \$ 0 \text {. }\end{array}$} \\
\hline
\end{tabular}

\footnotetext{
${ }^{1}$ We adjusted our definition of irrationality to account for the fact that ILS limit valuations to increments of five pence.

${ }^{2}$ In Section 3d of our Reply we report widespread inconsistency in risk preferences, another footprint of misconceptions.
} 
Table 1 reveals that subject beliefs appear to be directly influenced by whether they are placed in the position of seller or buyer. We define "boundary valuation asymmetry" as the asymmetric tendency for subjects to be more likely to report boundary valuations at or above the upper bound in selling (WTA) rounds and at or below the lower bound in buying (WTP) rounds. For example, 14\% of ILS's subjects reported boundary valuations at or above the upper bound when valuing as sellers in round \#7 and no subject chose the lower bound of zero. By comparison, when valuing the matched lottery as buyers in round \#11,5\% reported boundary valuations at or above the upper bound and $8 \%$ chose the lower bound or below. The results of one-tailed tests of equal proportions are displayed in Table 1. Five of the eight tests using ILS's data resulted in a statistically significant difference (at the 5\% level); four of the eight tests using our data produced similar results.

In short, when subjects report valuations as sellers, subjects are more likely to believe that the lottery outcome will be the higher payoff. Conversely, when subjects report valuations as buyers, they are more likely to believe that the lottery outcome will be the lower payoff.

Boundary asymmetries naturally imply the existence of "boundary gaps." An upper boundary gap is measured using only pairs of individual values for which the valuation as seller is on or above the upper bound and the valuation of the same individual as a buyer is below the upper bound. Similarly, to measure lower boundary gaps, we use only pairs for which the valuation as buyer is on or below the lower bound and the valuation as seller is above the lower bound. Boundary gaps suggest that the same subject perceives the same lottery as involving different subjective probabilities depending on whether the subject is valuing the lottery as a seller or a buyer.

Table 2 displays gaps, as measured by ILS, using a variety of subsets of the data. The first row of each panel ("all ILS data" and "all PZ data") reports gaps using all the data. These correspond to the gaps reported by ILS. ${ }^{3}$ The second row in each panel reports upper boundary gaps. The results demonstrate that the magnitude of gaps in the full dataset is driven substantially by relatively few individual ratios with seller valuations that are based on extreme beliefs. Likewise, the third row in each panel displays lower boundary gaps and reveals a similar impact by

\footnotetext{
${ }^{3}$ ILS reported gaps separately for our Type A and Type B lotteries. We pooled these subsets to construct Table 2.
} 
relatively few individual ratios with buyer valuations that are based on an extreme belief. The fourth row further demonstrates the impact of extreme asymmetric beliefs on lottery gaps. When those individuals exhibiting extreme beliefs of any kind as buyer or seller are removed from the data, the magnitudes of the gaps drop substantially.

\begin{tabular}{|c|c|c|c|c|c|}
\hline \multicolumn{6}{|c|}{ TABLE 2: BOUNDARY GAPS } \\
\hline \multicolumn{6}{|c|}{ ILS LOTTERY DATA } \\
\hline & L3/L6 & L7/L11 & L8/L12 & L9/L13 & L10/L14 \\
\hline \multicolumn{6}{|c|}{ MEAN WTA/WTP RATIO (MEDIAN RATIO WITH RESULTS FROM ONE-TAILED SIGNED RANK TEST } \\
\hline All ILS data & $\begin{array}{c}2.19\left(1.33^{\star \star \star}\right) \\
N=100\end{array}$ & $\begin{array}{c}1.53\left(1.26^{\star * \star}\right) \\
N=100\end{array}$ & $\begin{array}{c}1.37\left(1.16^{* \star \star}\right) \\
N=100\end{array}$ & $\begin{array}{c}1.11(1.00) \\
\mathrm{N}=100\end{array}$ & $\begin{array}{c}1.46\left(1.11^{\star \star *}\right) \\
N=100\end{array}$ \\
\hline $\begin{array}{c}\text { Upper } \\
\text { boundary gap }\end{array}$ & $\begin{array}{c}10.58\left(2.67^{\star \star}\right) \\
\mathrm{N}=7\end{array}$ & $\begin{array}{c}2.42\left(2.03^{\star \star \star}\right) \\
N=12\end{array}$ & $\begin{array}{c}2.76\left(3.00^{*}\right) \\
N=4\end{array}$ & $\begin{array}{c}2.20\left(2.33^{\star}\right) \\
N=4\end{array}$ & $\begin{array}{c}4.38\left(5.00^{\star}\right) \\
N=4\end{array}$ \\
\hline $\begin{array}{c}\text { Lower } \\
\text { boundary gap }\end{array}$ & $\begin{array}{c}6.43\left(2.50^{\star \star \star}\right) \\
N=15\end{array}$ & $\begin{array}{c}4.01\left(4.00^{* *}\right) \\
N=8\end{array}$ & $\begin{array}{c}2.27\left(2.24^{\star \star \star}\right) \\
N=18\end{array}$ & $\begin{array}{c}1.71\left(1.67^{\star \star \star}\right) \\
N=15\end{array}$ & $\begin{array}{c}3.06\left(2.50^{\star \star \star}\right) \\
N=15\end{array}$ \\
\hline $\begin{array}{l}\text { Both } \\
\text { valuations } \\
\text { inside the } \\
\text { bounds }\end{array}$ & $\begin{array}{c}1.36\left(1.15^{\star}\right) \\
\mathrm{N}=78\end{array}$ & $\begin{array}{c}1.26\left(1.16^{\star \star \star}\right) \\
N=81\end{array}$ & $\begin{array}{c}1.16\left(1.04^{\star \star \star}\right) \\
N=80\end{array}$ & $\begin{array}{c}1.00(1.00) \\
\mathrm{N}=83\end{array}$ & $\begin{array}{c}1.16(1.03) \\
\mathrm{N}=83\end{array}$ \\
\hline \multicolumn{6}{|c|}{ PZ LOTTERY DATA (POOLED ACROSS TYPE A AND B LOTTERIES) } \\
\hline & L3/L6 & L7/L11 & L8/L12 & L9/L13 & L10/L14 \\
\hline \multicolumn{6}{|c|}{ MEAN WTA/WTP RATIO (MEDIAN RATIO WITH RESULTS FROM ONE-TAILED SIGNED RANK TEST) } \\
\hline All PZ data & $\begin{array}{c}1.53\left(1.15^{\star \star \star}\right) \\
N=71^{a}\end{array}$ & $\begin{array}{c}1.56\left(1.20^{\star \star \star}\right) \\
N=74\end{array}$ & $\begin{array}{c}1.50\left(1.20^{\star \star \star}\right) \\
N=74\end{array}$ & $\begin{array}{c}1.68\left(1.03^{\star * \star}\right) \\
N=73\end{array}$ & $\begin{array}{c}1.32\left(1.04^{\star \star \star}\right) \\
N=74\end{array}$ \\
\hline $\begin{array}{c}\text { Upper } \\
\text { boundary gap }\end{array}$ & $\begin{array}{c}2.16\left(1.60^{\star *}\right) \\
N=5\end{array}$ & $\begin{array}{c}2.15\left(2.00^{* *}\right) \\
N=5\end{array}$ & $\begin{array}{c}1.77\left(1.44^{*}\right) \\
N=4\end{array}$ & $\mathrm{~N}=0$ & $\begin{array}{c}1.83\left(1.47^{*}\right) \\
N=4\end{array}$ \\
\hline $\begin{array}{c}\text { Lower } \\
\text { boundary gap }\end{array}$ & $\mathrm{N}=0$ & $\begin{array}{c}4.40\left(5.00^{* *}\right) \\
N=5\end{array}$ & $\begin{array}{c}4.00\left(4.05^{\star \star}\right) \\
N=5\end{array}$ & $\mathrm{~N}=0$ & $\begin{array}{c}8.00(8.00) \\
N=1\end{array}$ \\
\hline $\begin{array}{c}\text { Both } \\
\text { valuations } \\
\text { inside the } \\
\text { bounds }\end{array}$ & $\begin{array}{c}1.49\left(1.10^{\star * *}\right) \\
N=65\end{array}$ & $\begin{array}{c}1.31\left(1.15^{\star \star \star}\right) \\
N=63\end{array}$ & $\begin{array}{c}1.29\left(1.17^{\star * *}\right) \\
N=64\end{array}$ & $\begin{array}{c}1.68\left(1.03^{\star * *}\right) \\
N=73\end{array}$ & $\begin{array}{c}1.20\left(1.00^{\star *}\right) \\
N=67\end{array}$ \\
\hline
\end{tabular}

${ }^{\text {a }}$ Ratios for three subjects are undefined because lottery valued at $\$ 0$ as buyer in Round 6 . In Round 13 , one buyer valued the lottery at $\$ 0$. The sign test includes the $\$ 0$ bids.

${ }^{b} \mathrm{H}_{0}$ : adjusted WTA and WTP come from identical distributions (results from one-tailed test)

Importantly, boundary gaps demonstrate evidence of misconceptions and do not lend support to the preference function assumed by endowment effect theory. In the absence of special assumptions about the preference relation, an individual who values a lottery on the boundary of the value support should reveal the same value regardless of whether in the role of buyer or seller. This implies that boundary gaps are different from the standard interpretation of a valuation gap: a gap between WTA and WTA for the same good. ${ }^{4}$ Individuals revealing

\footnotetext{
${ }^{4}$ Very few ILS subjects valued the lotteries at or above the upper bound as both buyer and seller ( 2 for L3/6 and $\mathrm{L} 7 / 11 ; 1$ for L8/12, L9/13 and L10/14) and at or below the lower bound as both buyer and seller (0 for L3/6, L7/11,
} 
boundary gaps view the lottery from the buying perspective as a different lottery than the one considered from the selling perspective, even though the lotteries are identical (save the addition of some amount to both outcomes). In other words, boundary gaps imply that the actual properties of the lottery as perceived by the individual have changed from round to round and from selling perspective to buying perspective, presumably due to misconceptions about randomness. Hence, the very concept of a valuation gap is inappropriate.

The existence of the boundary gaps and the substantial reduction in gap magnitude when only non-suspect data are included suggest that misconceptions about the random device play a central role in the lottery valuation gaps. Furthermore, the existence of boundary asymmetries has substantial implications for the use of lotteries in the measurement of WTP-WTA gaps. If misconceptions about the random device cannot be controlled, and in particular, if the systematic violation of sophisticated beliefs cannot be avoided, then, as a matter of principle, lotteries valuations should not be used to measure WTA-WTP gaps, which assume that individuals value the same good as buyer and as seller. If the roles of seller and buyer trigger a change in subjective probabilities for the same lottery, then the lottery valued from the buying perspective is not the same as the lottery valued from the selling perspective. Unless subjects view the good as the same good from both perspectives, testing EET or even measuring a valuation gap using lotteries is impossible. Tversky and Kahneman (1991) were wise to move the science to the study of commodities when developing the foundations from which EET was constructed.

Finally, while gaps exist in the valuations that remain after removing suspect valuations, conclusions drawn from any remaining gap have questionable reliability if applied to EET. It is reasonable to believe that the forces that compel the reporting of suspect valuations might influence the valuations of subjects who stayed inside the bounds. More work is required to determine whether gaps would remain after properly controlling for misconceptions about random devices. In Section II, we discuss how our revealed theory methodology illuminates avenues through which the research can proceed.

$\mathrm{L} 8 / 12$ and L10/14, and 2 for L9/13). The same is true for our subjects (upper bound: 1 for L3/6, L7/11 and L8/12; 0 for L9/13 and 2 for L10/14; 0 for all lotteries for the lower bound). 


\section{Revealed theory methodology and controlling for lottery misconceptions}

Our study was based on the intuition that subject misconceptions about the preference elicitation device systematically impact valuations. Importantly, we recognized that there is no theory of misconceptions. To approach this seemingly intractable problem, we developed a "revealed theory" approach that rests on the assumption that procedures used by experimentalists to control for misconceptions in some sense reveal a theory of misconceptions. Our strategy was to cast a wide net by examining theories and employing procedures that others had suggested or used in relation to misconceptions and the preference elicitation device. Using this method, we incorporated them all into a single set of procedures with the hope that misconceptions about the elicitation device might be adequately controlled. As we did not intend to use the lottery data to test EET, we did not develop procedures to control for misconceptions about random devices associated with lotteries.

When we employed the revealed theory procedures in mug rounds, the valuation gap disappeared. Thus, our mug data demonstrate that the mug experiments do not support EET. Given that there is no well-defined theory of misconceptions that can be specified as a theoretical alternative to EET, however, the data fall short of supporting a conclusion that the gap in mug valuations is caused by some specific theory of misconceptions. Instead, application of the revealed theory method produces a collection of potential theories (PZ, p. 531). This implies that no clear theory of misconceptions can be formulated to apply in all circumstances and that the set of controls will depend on the features of the experiment that might lead to misconceptions, including features of the goods. For these reasons, to correctly apply revealed theory methodology, one must appeal to the literatures that specifically address features that might trigger misconceptions.

Neither PZ nor ILS apply revealed theory methodology in the lottery round design. Neither design considers the literature that explores possible misconceptions associated with special features of lotteries. It is well known that lotteries can trigger difficulties in addition to any misconception that might relate to the elicitation device and that these must be addressed before reported valuations can be used to test any theory of preference. Experimenters have studied important issues related to the random process and its role in influencing subjects' beliefs (i.e., subjective probabilities) about what actions might be optimal. Depending on the factors that 
influence beliefs as subjects face lotteries, values placed on the same lottery can change from round to round, as we demonstrated in the previous section. The experimenter, being unable to observe the subject's changing beliefs, unknowingly collects data that are contaminated for the purpose of testing any theory assuming consistent preferences. This problem is especially troublesome when the theory rests on a particular shape of preference, as does prospect theory.

To properly apply revealed theory methodology to remove misconceptions about random devices in order to test theories of preferences over lotteries, the literature warns that one must attend to numerous types of misconceptions related to random devices. The challenge seems to stem from difficulties some individuals have with the notion of randomness itself. For example, some of our subjects reported believing that they could accurately guess the lottery outcomes, a belief supported by ILS's and our lottery data. If a subject believes he can accurately predict the outcome of a particular lottery and the prediction depends on whether he owns the lottery, then the subject's (unobserved) subjective probabilities, and thus the subject's valuation of the same lottery, might change from round to round. Such changing beliefs can be motivated by imagined patterns in historical data, theories based on the physical properties of random devices, or even impulses that cause people to believe that some outcomes are more likely than others. Such beliefs are symptomatic of a disconnect between the probabilities as understood by the experimenter and the actual beliefs held by subjects.

The nature of this disconnect requires study and, in fact, has been studied in a variety of ways. One of the most dramatic examples of the disconnect is the number of offers to pay more for a lottery than the maximum it could pay (or asking for less than the minimum payoff), as observed by both ILS and us. Keren and Willemsen (2008) connect this mistake to misconceptions over random devices. Camerer (1989) and Bossaerts and Plott (2004) report findings suggesting that individuals tend not to accept the notion of independence. How to train subjects away from these tendencies is not obvious, but the literature suggests ideas including the use of formal training models (Offerman et al. 2009) and training methods that work through subject involvement in the lottery procedures (Fong and McCabe, 1999).

While on the one hand paradoxes (e.g., Allais (1953) and Ellsberg (1961)) and anomalies (e.g., overconfidence, beliefs relating to low probability events) abound, several findings suggest that 
attitude formation has an underlying structure that leads to the eventual understanding of or an effective way of dealing with random processes (Gaissmaier and Schooler, 2008; Gigerenzer et al., 2008). Camilleri and Newell (2009) give subjects an opportunity to value hundreds of lotteries. ${ }^{5}$ Roth (2005) has directly studied whether observed lottery gaps are related to the underlying riskiness of lotteries. The application of revealed theory methodology to lottery rounds should take into account these and other such studies in fashioning controls for misconceptions about randomness.

\section{References}

Allais, Maurice. 1953. "Le comportement de l'homme rationnel devant le risque: critique des postulats et axiomes de l'école Américaine." Econometrica 21:503-46.

Bossaerts, Peter and Plott, Charles R. 2004. "Basic Principles of Asset Pricing Theory: Evidence from Large-Scale Experimental Financial Markets." Review of Finance, 8:135-69.

Camilleri, Adrian R. and Newell, Ben R. 2009. "The role of representation in experience-based choice." Judgment and Decision Making, 4(7) 518-29.

Camerer, Colin. 1989. "Does the Basketball Market Believe in the 'Hot Hand'?” American Economic Review, 79:1257-61.

Ellsberg, Daniel. 1961. "Risk, Ambiguity, and the Savage Axioms." Quarterly Journal of Economics 75(4):643-69.

Fong, Christina and McCabe, Kevin. 1999. “Are decisions under risk malleable?" Proceedings of the National Academy of Science, 96:10927-32.

Gaissmaier, Wolfgang and Schooler, Lael J. 2008. "The Smart Potential Behind Probability Matching." Cognition, 109:416-22.

Gigerenzer, Gerd; Hertwig, Ralph; Hofferage, Ulrich and Sedlmeier, Peter. 2008. "Cognitive Illusions Reconsidered.” In Handbook of Experimental Economic Results, ed. Charles R. Plott and Vernon L. Smith, 1018- 33. North Holland.

Isoni, Andrea; Loomes, Graham and Sugden, Robert. 201x. "The Willingness to Pay-Willingness to Accept Gaps, the 'Endowment Effect,' Subject Misconceptions, and Experimental Procedures for Eliciting Valuations: A Reassessment," American Economic Review, forthcoming.

Keren, Gideon and Willemsen, Martijn C. 2008. "Decision Anomalies, Experimenter Assumptions, and Participants' Comprehension: Revaluating the Uncertainty Effect." Journal of Behavioral Decision Making, 22(3):301-17.

\footnotetext{
${ }^{5}$ By comparison, ILS's and our lottery data are collected after only two unpaid practice rounds.
} 
Offerman, Theo; Sonnemans, Joep; Van De Kuilen, Gijs and Walker, Peter P. 2009. "A Truth Serum for Non-Bayesians: Correcting Proper Scoring Rules for Risk Attitudes." Review of Economic Studies, 76(4):1461-89.

Risen, Jane L. and Gilovich, Thomas. 2007. "Another Look at Why People Are Reluctant to Exchange Lottery Tickets." Journal of Personality and Social Psychology, 93(1):12-22.

Roth, Gerrit. 2005. "Predicting the Gap Between Willingness to Accept and Willingness to Pay." $\mathrm{PhD}$ diss. Munich Graduate School of Economics.

Tversky, Amos, and Kahneman, Daniel. 1991. "Loss Aversion in Riskless Choice: A ReferenceDependent Model." Quarterly Journal of Economics, 106(4):1039-61. 


\title{
Appendix Two to Endowment Effect Theory, \\ Subject Misconceptions and Enhancement Effect Theory: A Reply to Isoni, Loomes, and Sugden
}

\begin{abstract}
The data included in this file were collected in conjunction with experiments reported in Charles R. Plott and Kathryn Zeiler. 2005. The Willingness to Pay-Willingness to Accept Gap, the "Endowment Effect," Subject Misconceptions, and Experimental Procedures for Eliciting Valuations, American Economic Review 95(3).
\end{abstract}

We include these notes to provide information related to our purposes for designing the lottery rounds as we did. Examiners of these data should keep in mind the following. First, these data resulted from a training exercise and not from an experimental design that would be appropriate for comparisons of treatments designed to measure the WTP-WTA gap. Second, the procedures were not designed to produce evidence about when misconceptions exist and how they are removed. Thus, interpretations of these training data will be murky at best.

With respect to the first point, for example, the sequence of lotteries was chosen for an impact on training and understanding as opposed to experimental controls for measurement of a gap. In particular, all WTA responses were elicited before any of the WTP responses. We wanted subjects to understand the type of mechanism (i.e., selling using BDM), the one least familiar to them, before explaining a different one (i.e., buying using BDM). Thus, any observed patterns of behavior are confounded by learning, instruction, corrections, answered questions, different levels of experience with the elicitation mechanism, beliefs about the randomization device and other subtle events.

With respect to the second point, the confounding of variables mentioned above leads to patterns in the data that can be interpreted in a number of different ways, both in support of and against an endowment effect interpretation of a gap. Basically, we can find support in these data for any story. For example, to support "endowment effect" theory we would aggregate all the practice round data and test for a WTA/WTP gap. Upon doing this we find a significant difference between WTA and WTP. Thus, following the procedures used in many papers in which a gap is reported, we could report that we observe a gap (despite the fact that gaps are not expected to appear for lotteries, according to endowment effect theory advocates).

On the other hand, the data can be used to challenge the endowment effect interpretation of a gap. Based on commonly held ideas about misconceptions, we would expect responses in earlier rounds (i.e., WTA rounds) to be clouded by misconceptions moreso than those in later rounds. Misconceptions in WTA rounds lead to responses that exceed true valuations. As reported in the literature, when subjects gain experience with the elicitation mechanism WTA falls toward WTP. As they develop an understanding of how to value lotteries and move into the later WTP rounds, they lower their responses to correspond more closely to their true valuations. So, the pattern is consistent with the theory that misunderstandings are removed with practice.

In addition, results from more focused tests reject the "endowment effect" theory in favor of a theory of misconceptions. Consider the number of responses that are either within a penny or so of the minimum value that a lottery pays and responses that are at the maximum value that a lottery pays. Such responses strongly suggest some sort of misconception that should go away once revealed to the subjects. The table below contains the number of such decisions during the first two rounds of the WTA and WTP sessions. Notice the dramatic asymmetry that suggests a tendency toward the maximum in the WTA rounds and toward the minimum in the WTP rounds. 


\begin{tabular}{|l||c|c|}
\hline & $\begin{array}{c}\text { number bidding the } \\
\text { minimum possible }\end{array}$ & $\begin{array}{c}\text { number bidding the } \\
\text { maximum possible }\end{array}$ \\
\hline WTA (first two rounds) & 3 & 11 \\
\hline WTP (first two rounds) & 11 & 2 \\
\hline
\end{tabular}

There are additional measures that provide insights. Under a common assumption of risk aversion one would expect the stated value of a lottery to fall below the expected value. Using the behavior observed in asset market experiments and in auction experiments as a baseline, one might reasonably interpret stated values above the expected value to be an indicator of some sort of misunderstanding that should go away with experience. That is exactly what we see in these data. For example, the number of WTA above the expected value is 35, 26, 27 and 20 respectively for rounds 7, 8, 9 and 10 (By contrast, the average number of WTP above the expected value per round is 16 and without trend).

Of course, risk seeking behavior itself can be used to make a case for prospect theory and endowment effect theory. For example, an interpretation of the gap using prospect theory suggests that individuals view selling as a loss (where they are risk seeking according to some of the older, (perhaps abandoned) versions of prospect theory) and buying as a gain (where they are risk averse). So, one can apply endowment theory to predict the observed aggregate patterns: that WTA will be above expected value and WTP will be below expected value.

We can turn that story upside down, however, by observing in these data patterns of individual behavior that produce strong support against prospect theory. One can ask if any individual subject displayed behavior consistent with that version of prospect theory, namely risk seeking when reporting WTA and risk avoiding when reporting WTP. Of course, we know that the question is unfair because of the learning that is taking place and other variables that are changing across these sessions. Nevertheless, when considering each round individually, we observe that only 8 of 74 subjects report valuations that are consistently above the expected value in the WTA trials. Moreover, no subject displays behavior predicted by prospect theory (i.e., values above expected value in WTA and below in WTP) throughout all lottery rounds.

While such observations run counter to predictions made by prospect theory, we think that this is an inappropriate interpretation and that it only illustrates the danger of aggregating data across events to test for a WTA/WTP gap. As one might expect in training rounds, there is an overall lack of consistency at the individual level. For example, only 12 out of 74 subjects expressed values that were consistently above or consistently below the expected value of the lottery in WTA rounds, and only 21 out of 74 were consistently above or consistently below the expected value of the lottery in WTP rounds (9 out of 74 were consistently risk neutral under WTA and 8 out of 74 were consistently risk neutral under WTP). Basically, 58 out of 74 subjects exhibited some sort of inconsistency between risk seeking and risk adverse behavior during WTA rounds or WTP rounds.

We did conduct a few post-experiment interviews that suggested some explanations for the behaviors. These included a failure of subjects to accept independence across trials and to understand randomness generally. That phenomenon could have created sequencing effects due to lottery outcomes. There appears to be a "final decision" effect, which is common in experiments. Some individuals consistently make inexplicable decisions (e.g., tending to value a lottery at the maximum it can pay) while others modify such behaviors. Now, having conducted the training sessions and examined the data, we know much more information that might enable the development of designs to isolate and track misconceptions of various sorts.

In summary, we think it unwise to use these data as part of the scientific discussion or to publish statistics from these data without extensive discussions highlighting the issues mentioned here. As training exercises, the lottery rounds clearly had an impact even though residuals of misconceptions might have remained. Given the proper forum, focused on procedures and learning, however, the data might play a useful role in shaping our understanding of experimental methodology. 
Summary of Lottery Data

Plott/Zeiler

USC Law School (31 subjects)

Mug valuations measured AFTER lottery rounds.
Notes: Mug data appears in bold type.

All highlighted offers were made by subjects acting as sellers.

Each column under the heading "individual data" includes responses for one subject. Type As and Type Bs were presented with different lotteries (subjects were staggered so that they could not see each other's responses).

\begin{tabular}{|c|c|c|c|c|c|c|c|c|c|c|c|}
\hline \multicolumn{12}{|c|}{ February 28, 2001} \\
\hline \multicolumn{5}{|c|}{ Lottery: TYPE A } & \multicolumn{3}{|c|}{ summary statistics } & \multicolumn{4}{|c|}{ Individual Data } \\
\hline $\begin{array}{c}\text { prob of } \\
\text { A }\end{array}$ & A & prob of $B$ & B & EV & mean & median & std dev & subj 1 & subj 2 & subj 3 & subj 4 \\
\hline $50 \%$ & 0.20 & $50 \%$ & 0.20 & 0.20 & 0.20 & 0.20 & 0.00 & 0.20 & 0.20 & 0.20 & 0.20 \\
\hline $50 \%$ & 0.35 & $50 \%$ & 0.35 & 0.35 & 0.35 & 0.35 & 0.00 & 0.35 & 0.35 & 0.35 & 0.35 \\
\hline $30 \%$ & 0.70 & $70 \%$ & -0.20 & 0.07 & 0.08 & 0.08 & 0.06 & 0.00 & 0.15 & 0.05 & 0.10 \\
\hline $50 \%$ & 0.30 & $50 \%$ & 0.30 & 0.30 & 0.30 & 0.30 & 0.00 & 0.30 & 0.30 & 0.30 & 0.30 \\
\hline $50 \%$ & 0.45 & $50 \%$ & 0.45 & 0.45 & 0.45 & 0.45 & 0.00 & 0.45 & 0.45 & 0.45 & 0.45 \\
\hline $30 \%$ & 0.80 & $70 \%$ & -0.10 & 0.17 & 0.11 & 0.11 & 0.11 & 0.00 & 0.21 & 0.02 & 0.20 \\
\hline $70 \%$ & 7.00 & $30 \%$ & 0.00 & 4.90 & 2.78 & 2.55 & 0.93 & 3.00 & 2.10 & 2.00 & 4.00 \\
\hline $40 \%$ & 5.00 & $60 \%$ & 0.00 & 2.00 & 1.50 & 1.50 & 0.58 & 1.00 & 2.00 & 1.00 & 2.00 \\
\hline $50 \%$ & 8.00 & $50 \%$ & -4.00 & 2.00 & 1.00 & 1.00 & 1.15 & 0.00 & 2.00 & 0.00 & 2.00 \\
\hline $30 \%$ & 10.00 & $70 \%$ & 0.00 & 3.00 & 2.63 & 1.75 & 3.20 & 0.00 & 7.00 & 0.50 & 3.00 \\
\hline $70 \%$ & 8.00 & $30 \%$ & 1.00 & 5.90 & 3.60 & 3.35 & 1.63 & 2.00 & 2.70 & 4.00 & 5.70 \\
\hline $40 \%$ & 6.00 & $60 \%$ & 1.00 & 3.00 & 2.00 & 2.00 & 0.82 & 2.00 & 1.00 & 2.00 & 3.00 \\
\hline $50 \%$ & 9.00 & $50 \%$ & -3.00 & 3.00 & 1.00 & 1.00 & 0.82 & 0.00 & 1.00 & 1.00 & 2.00 \\
\hline \multirow[t]{2}{*}{$30 \%$} & 11.00 & $70 \%$ & 1.00 & 4.00 & 2.00 & 1.50 & 1.35 & 1.50 & 1.00 & 1.50 & 4.00 \\
\hline & & & & & \multicolumn{3}{|c|}{ MUG } & 6.00 & 3.00 & 4.00 & 11.00 \\
\hline \multicolumn{5}{|c|}{ Lottery: TYPE B } & \multicolumn{3}{|c|}{ summary statistics } & \multicolumn{4}{|c|}{ Individual Data } \\
\hline $\begin{array}{c}\text { prob of } \\
\text { A }\end{array}$ & A & prob of B & $\mathrm{B}$ & EV & mean & median & std dev & subj 5 & subj 6 & subj 7 & subj 8 \\
\hline $50 \%$ & 0.20 & $50 \%$ & 0.20 & 0.20 & 0.20 & 0.20 & 0.00 & 0.20 & 0.20 & 0.20 & 0.20 \\
\hline $50 \%$ & 0.35 & $50 \%$ & 0.35 & 0.35 & 0.35 & 0.35 & 0.00 & 0.35 & 0.35 & 0.35 & 0.35 \\
\hline $30 \%$ & -0.20 & $70 \%$ & 0.70 & 0.43 & 0.33 & 0.35 & 0.21 & 0.20 & 0.10 & 0.50 & 0.50 \\
\hline $50 \%$ & 0.30 & $50 \%$ & 0.30 & 0.30 & 0.30 & 0.30 & 0.00 & 0.30 & 0.30 & 0.30 & 0.30 \\
\hline $50 \%$ & 0.45 & $50 \%$ & 0.45 & 0.45 & 0.45 & 0.45 & 0.00 & 0.45 & 0.45 & 0.45 & 0.45 \\
\hline $30 \%$ & -0.10 & $70 \%$ & 0.80 & 0.53 & 0.55 & 0.53 & 0.16 & 0.40 & 0.75 & 0.45 & 0.60 \\
\hline $70 \%$ & 0.00 & $30 \%$ & 7.00 & 2.10 & 2.75 & 2.25 & 1.94 & 2.50 & 5.50 & 2.00 & 1.00 \\
\hline $40 \%$ & 0.00 & $60 \%$ & 5.00 & 3.00 & 2.81 & 2.63 & 0.90 & 2.25 & 4.00 & 2.00 & 3.00 \\
\hline $50 \%$ & -4.00 & $50 \%$ & 8.00 & 2.00 & 2.81 & 1.88 & 2.87 & 1.75 & 2.00 & 7.00 & 0.50 \\
\hline $30 \%$ & 0.00 & $70 \%$ & 10.00 & 7.00 & 6.50 & 6.50 & 2.38 & 4.00 & 8.00 & 9.00 & 5.00 \\
\hline $70 \%$ & 1.00 & $30 \%$ & 8.00 & 3.10 & 1.94 & 1.88 & 0.43 & 1.75 & 2.50 & 2.00 & 1.50 \\
\hline $40 \%$ & 1.00 & $60 \%$ & 6.00 & 4.00 & 2.63 & 2.50 & 0.63 & 2.00 & 3.50 & 2.50 & 2.50 \\
\hline $50 \%$ & -3.00 & $50 \%$ & 9.00 & 3.00 & 2.81 & 2.50 & 1.82 & 2.00 & 5.25 & 1.00 & 3.00 \\
\hline \multirow[t]{2}{*}{$30 \%$} & 1.00 & $70 \%$ & 11.00 & 8.00 & 7.81 & 7.63 & 2.79 & 6.00 & 9.25 & 5.00 & 11.00 \\
\hline & & & & & & MUG & & 5.00 & 8.00 & 0.00 & 7.00 \\
\hline
\end{tabular}




\begin{tabular}{|c|c|c|c|c|c|c|c|c|c|c|}
\hline \multicolumn{11}{|c|}{ March 1, 2001} \\
\hline \multicolumn{5}{|c|}{ Lottery: TYPE A } & \multicolumn{3}{|c|}{ summary statistics } & \multicolumn{2}{|c|}{ Individual Data } & \\
\hline $\begin{array}{c}\text { prob of } \\
A\end{array}$ & A & prob of $B$ & B & EV & mean & median & std dev & subj 9 & subj 10 & \\
\hline $50 \%$ & 0.20 & $50 \%$ & 0.20 & 0.20 & 0.20 & 0.20 & 0.00 & 0.20 & 0.20 & \\
\hline $50 \%$ & 0.35 & $50 \%$ & 0.35 & 0.35 & 0.35 & 0.35 & 0.00 & 0.35 & 0.35 & \\
\hline $30 \%$ & 0.70 & $70 \%$ & -0.20 & 0.07 & 0.15 & 0.15 & 0.00 & 0.15 & 0.15 & \\
\hline $50 \%$ & 0.30 & $50 \%$ & 0.30 & 0.30 & 0.30 & 0.30 & 0.00 & 0.30 & 0.30 & \\
\hline $50 \%$ & 0.45 & $50 \%$ & 0.45 & 0.45 & 0.45 & 0.45 & 0.00 & 0.45 & 0.45 & \\
\hline $30 \%$ & 0.80 & $70 \%$ & -0.10 & 0.17 & 0.14 & 0.14 & 0.06 & 0.18 & 0.10 & \\
\hline $70 \%$ & 7.00 & $30 \%$ & 0.00 & 4.90 & 5.13 & 5.13 & 0.18 & 5.00 & 5.25 & \\
\hline $40 \%$ & 5.00 & $60 \%$ & 0.00 & 2.00 & 2.08 & 2.08 & 0.11 & 2.00 & 2.15 & \\
\hline $50 \%$ & 8.00 & $50 \%$ & -4.00 & 2.00 & 2.00 & 2.00 & 0.00 & 2.00 & 2.00 & \\
\hline $30 \%$ & 10.00 & $70 \%$ & 0.00 & 3.00 & 3.50 & 3.50 & 0.71 & 3.00 & 4.00 & \\
\hline $70 \%$ & 8.00 & $30 \%$ & 1.00 & 5.90 & 5.95 & 5.95 & 0.07 & 5.90 & 6.00 & \\
\hline $40 \%$ & 6.00 & $60 \%$ & 1.00 & 3.00 & 3.10 & 3.10 & 0.14 & 3.00 & 3.20 & \\
\hline $50 \%$ & 9.00 & $50 \%$ & -3.00 & 3.00 & 3.00 & 3.00 & 0.00 & 3.00 & 3.00 & \\
\hline \multirow[t]{2}{*}{$30 \%$} & 11.00 & $70 \%$ & 1.00 & 4.00 & 3.50 & 3.50 & 0.71 & 4.00 & 3.00 & \\
\hline & & & & & \multicolumn{3}{|c|}{ MUG } & 4.17 & 6.00 & \\
\hline \multicolumn{5}{|c|}{ Lottery: TYPE B } & \multicolumn{3}{|c|}{ summary statistics } & \multicolumn{3}{|c|}{ Individual Data } \\
\hline $\begin{array}{c}\text { prob of } \\
A\end{array}$ & A & prob of $B$ & B & EV & mean & median & std dev & subj 11 & subj 12 & subj 13 \\
\hline $50 \%$ & 0.20 & $50 \%$ & 0.20 & 0.20 & 0.20 & 0.20 & 0.00 & 0.20 & 0.20 & 0.20 \\
\hline $50 \%$ & 0.35 & $50 \%$ & 0.35 & 0.35 & 0.35 & 0.35 & 0.00 & 0.35 & 0.35 & 0.35 \\
\hline $30 \%$ & -0.20 & $70 \%$ & 0.70 & 0.43 & 0.47 & 0.50 & 0.06 & 0.50 & 0.50 & 0.40 \\
\hline $50 \%$ & 0.30 & $50 \%$ & 0.30 & 0.30 & 0.30 & 0.30 & 0.00 & 0.30 & 0.30 & 0.30 \\
\hline $50 \%$ & 0.45 & $50 \%$ & 0.45 & 0.45 & 0.45 & 0.45 & 0.00 & 0.45 & 0.45 & 0.45 \\
\hline $30 \%$ & -0.10 & $70 \%$ & 0.80 & 0.53 & 0.57 & 0.50 & 0.12 & 0.70 & 0.50 & 0.50 \\
\hline $70 \%$ & 0.00 & $30 \%$ & 7.00 & 2.10 & 2.33 & 2.00 & 0.58 & 2.00 & 2.00 & 3.00 \\
\hline $40 \%$ & 0.00 & $60 \%$ & 5.00 & 3.00 & 2.75 & 2.75 & 0.75 & 2.75 & 2.00 & 3.50 \\
\hline $50 \%$ & -4.00 & $50 \%$ & 8.00 & 2.00 & 2.67 & 2.00 & 1.15 & 4.00 & 2.00 & 2.00 \\
\hline $30 \%$ & 0.00 & $70 \%$ & 10.00 & 7.00 & 7.00 & 7.00 & 0.00 & 7.00 & 7.00 & 7.00 \\
\hline $70 \%$ & 1.00 & $30 \%$ & 8.00 & 3.10 & 2.53 & 2.50 & 0.06 & 2.60 & 2.50 & 2.50 \\
\hline $40 \%$ & 1.00 & $60 \%$ & 6.00 & 4.00 & 3.42 & 3.50 & 0.38 & 3.50 & 3.00 & 3.75 \\
\hline $50 \%$ & -3.00 & $50 \%$ & 9.00 & 3.00 & 3.00 & 3.00 & 0.00 & 3.00 & 3.00 & 3.00 \\
\hline \multirow[t]{2}{*}{$30 \%$} & 1.00 & $70 \%$ & 11.00 & 8.00 & 7.00 & 8.00 & 2.18 & 8.50 & 4.50 & 8.00 \\
\hline & & & & & & MUG & & 3.50 & 6.00 & 3.75 \\
\hline
\end{tabular}




\section{March 2, 2001}

\begin{tabular}{|ccccc|}
\hline \multicolumn{5}{c|}{ Lottery: TYPE A } \\
\hline $\begin{array}{c}\text { prob of } \\
\text { A }\end{array}$ & A & prob of B & B & EV \\
$50 \%$ & 0.20 & $50 \%$ & 0.20 & 0.20 \\
$50 \%$ & 0.35 & $50 \%$ & 0.35 & 0.35 \\
$30 \%$ & 0.70 & $70 \%$ & -0.20 & 0.07 \\
$50 \%$ & 0.30 & $50 \%$ & 0.30 & 0.30 \\
$50 \%$ & 0.45 & $50 \%$ & 0.45 & 0.45 \\
$30 \%$ & 0.80 & $70 \%$ & -0.10 & 0.17 \\
$70 \%$ & 7.00 & $30 \%$ & 0.00 & 4.90 \\
$40 \%$ & 5.00 & $60 \%$ & 0.00 & 2.00 \\
$50 \%$ & 8.00 & $50 \%$ & -4.00 & 2.00 \\
$30 \%$ & 10.00 & $70 \%$ & 0.00 & 3.00 \\
$70 \%$ & 8.00 & $30 \%$ & 1.00 & 5.90 \\
$40 \%$ & 6.00 & $60 \%$ & 1.00 & 3.00 \\
$50 \%$ & 9.00 & $50 \%$ & -3.00 & 3.00 \\
$30 \%$ & 11.00 & $70 \%$ & 1.00 & 4.00
\end{tabular}

\begin{tabular}{|ccccccc|}
\hline \multicolumn{3}{|c|}{ summary statistics } & \multicolumn{4}{c|}{ Individual Data } \\
\cline { 5 - 7 } mean & median & std dev & subj 14 & subj 15 & subj 16 \\
\hline 0.20 & 0.20 & 0.00 & 0.20 & 0.20 & 0.20 \\
0.35 & 0.35 & 0.00 & 0.35 & 0.35 & 0.35 \\
0.10 & 0.10 & 0.10 & 0.10 & 0.00 & 0.20 \\
0.30 & 0.30 & 0.00 & 0.30 & 0.30 & 0.30 \\
0.45 & 0.45 & 0.00 & 0.45 & 0.45 & 0.45 \\
0.24 & 0.25 & 0.07 & 0.25 & 0.17 & 0.30 \\
4.80 & 4.90 & 0.26 & 5.00 & 4.90 & 4.50 \\
2.33 & 2.00 & 0.58 & 3.00 & 2.00 & 2.00 \\
2.00 & 2.00 & 0.00 & 2.00 & 2.00 & 2.00 \\
3.33 & 3.00 & 0.58 & 4.00 & 3.00 & 3.00 \\
5.13 & 5.90 & 1.87 & 6.50 & 5.90 & 3.00 \\
2.98 & 3.00 & 0.73 & 3.70 & 3.00 & 2.25 \\
3.17 & 3.00 & 0.29 & 3.50 & 3.00 & 3.00 \\
4.14 & 4.00 & 0.71 & 4.91 & 4.00 & 3.50 \\
& & & & 13.75 & $\mathbf{0 . 0 0}$ & $\mathbf{9 . 5 0}$
\end{tabular}

\begin{tabular}{|ccccc|}
\hline \multicolumn{5}{c}{ Lottery: TYPE B } \\
\hline prob of & A & prob of B & B & EV \\
A & & & & \\
$50 \%$ & 0.20 & $50 \%$ & 0.20 & 0.20 \\
$50 \%$ & 0.35 & $50 \%$ & 0.35 & 0.35 \\
$30 \%$ & -0.20 & $70 \%$ & 0.70 & 0.43 \\
$50 \%$ & 0.30 & $50 \%$ & 0.30 & 0.30 \\
$50 \%$ & 0.45 & $50 \%$ & 0.45 & 0.45 \\
$30 \%$ & -0.10 & $70 \%$ & 0.80 & 0.53 \\
$70 \%$ & 0.00 & $30 \%$ & 7.00 & 2.10 \\
$40 \%$ & 0.00 & $60 \%$ & 5.00 & 3.00 \\
$50 \%$ & -4.00 & $50 \%$ & 8.00 & 2.00 \\
$30 \%$ & 0.00 & $70 \%$ & 10.00 & 7.00 \\
$70 \%$ & 1.00 & $30 \%$ & 8.00 & 3.10 \\
$40 \%$ & 1.00 & $60 \%$ & 6.00 & 4.00 \\
$50 \%$ & -3.00 & $50 \%$ & 9.00 & 3.00 \\
$30 \%$ & 1.00 & $70 \%$ & 11.00 & 8.00
\end{tabular}

\begin{tabular}{|lllllllll|}
\hline \multicolumn{3}{|c}{ summary statistics } & \multicolumn{5}{c|}{ Individual Data } \\
\cline { 6 - 8 } mean & median & std dev & subj 17 & subj 18 & subj 19 & subj 20 & subj 21 \\
\hline 0.20 & 0.20 & 0.00 & 0.20 & 0.20 & 0.20 & 0.20 & 0.20 \\
0.35 & 0.35 & 0.00 & 0.35 & 0.35 & 0.35 & 0.35 & 0.35 \\
0.29 & 0.40 & 0.18 & 0.00 & 0.43 & 0.40 & 0.20 & 0.40 \\
0.30 & 0.30 & 0.00 & 0.30 & 0.30 & 0.30 & 0.30 & 0.30 \\
0.45 & 0.45 & 0.00 & 0.45 & 0.45 & 0.45 & 0.45 & 0.45 \\
0.43 & 0.53 & 0.18 & 0.20 & 0.53 & 0.60 & 0.26 & 0.55 \\
2.32 & 2.50 & 0.56 & 1.50 & 2.10 & 3.00 & 2.50 & 2.50 \\
3.19 & 3.00 & 1.20 & 2.00 & 3.00 & 5.20 & 2.75 & 3.00 \\
1.40 & 2.00 & 0.89 & 0.00 & 2.00 & 2.00 & 1.00 & 2.00 \\
6.75 & 6.50 & 1.46 & 6.25 & 7.00 & 9.00 & 6.50 & 5.00 \\
\hline 2.65 & 2.46 & 0.77 & 2.46 & 3.10 & 1.94 & 2.00 & 3.75 \\
3.42 & 3.50 & 0.60 & 2.85 & 4.00 & 4.00 & 2.75 & 3.50 \\
2.00 & 2.00 & 1.31 & 1.26 & 3.00 & 2.00 & 0.25 & 3.50 \\
6.80 & 7.50 & 2.51 & 4.50 & 10.00 & 7.50 & 4.00 & 8.00 \\
& MUG & & $\mathbf{1 . 6 2}$ & $\mathbf{1 . 0 0}$ & $\mathbf{6 . 5 0}$ & $\mathbf{3 . 7 5}$ & $\mathbf{5 . 0 0}$ \\
\hline
\end{tabular}




\section{March 21, 2001}

\begin{tabular}{|ccccc|}
\hline \multicolumn{5}{c|}{ Lottery: TYPE A } \\
\hline $\begin{array}{c}\text { prob of } \\
\text { A }\end{array}$ & A & prob of B & B & EV \\
$50 \%$ & 0.20 & $50 \%$ & 0.20 & 0.20 \\
$50 \%$ & 0.35 & $50 \%$ & 0.35 & 0.35 \\
$30 \%$ & 0.70 & $70 \%$ & -0.20 & 0.07 \\
$50 \%$ & 0.30 & $50 \%$ & 0.30 & 0.30 \\
$50 \%$ & 0.45 & $50 \%$ & 0.45 & 0.45 \\
$30 \%$ & 0.80 & $70 \%$ & -0.10 & 0.17 \\
$70 \%$ & 7.00 & $30 \%$ & 0.00 & 4.90 \\
$40 \%$ & 5.00 & $60 \%$ & 0.00 & 2.00 \\
$50 \%$ & 8.00 & $50 \%$ & -4.00 & 2.00 \\
$30 \%$ & 10.00 & $70 \%$ & 0.00 & 3.00 \\
$70 \%$ & 8.00 & $30 \%$ & 1.00 & 5.90 \\
$40 \%$ & 6.00 & $60 \%$ & 1.00 & 3.00 \\
$50 \%$ & 9.00 & $50 \%$ & -3.00 & 3.00 \\
$30 \%$ & 11.00 & $70 \%$ & 1.00 & 4.00
\end{tabular}

\begin{tabular}{|c|c|c|c|c|c|c|}
\hline \multicolumn{3}{|c|}{ summary statistics } & \multicolumn{4}{|c|}{ Individual Data } \\
\hline mean & median & std dev & subj 22 & subj 23 & subj 24 & subj 25 \\
\hline 0.20 & 0.20 & 0.00 & 0.20 & 0.20 & 0.20 & 0.20 \\
\hline 0.35 & 0.35 & 0.00 & 0.35 & 0.35 & 0.35 & 0.35 \\
\hline 0.15 & 0.10 & 0.17 & 0.10 & 0.40 & 0.01 & 0.10 \\
\hline 0.30 & 0.30 & 0.00 & 0.30 & 0.30 & 0.30 & 0.30 \\
\hline 0.45 & 0.45 & 0.00 & 0.45 & 0.45 & 0.45 & 0.45 \\
\hline 0.23 & 0.26 & 0.09 & 0.22 & 0.30 & 0.10 & 0.30 \\
\hline 4.59 & 4.43 & 1.24 & 3.60 & 3.50 & 6.00 & 5.25 \\
\hline 2.50 & 2.50 & 0.58 & 3.00 & 2.00 & 3.00 & 2.00 \\
\hline 3.19 & 3.38 & 0.90 & 3.75 & 2.00 & 4.00 & 3.00 \\
\hline 2.75 & 2.75 & 0.65 & 2.50 & 3.50 & 2.00 & 3.00 \\
\hline 4.75 & 4.38 & 1.67 & 3.75 & 3.25 & 7.00 & 5.00 \\
\hline 2.06 & 2.13 & 0.88 & 1.75 & 2.50 & 1.00 & 3.00 \\
\hline 2.94 & 3.00 & 0.52 & 2.25 & 3.00 & 3.00 & 3.50 \\
\hline \multirow[t]{2}{*}{2.63} & 2.51 & 0.66 & 2.26 & 3.50 & 2.00 & 2.75 \\
\hline & MUG & & 3.75 & 6.00 & 5.00 & 10.00 \\
\hline
\end{tabular}

\begin{tabular}{|ccccc|}
\hline \multicolumn{5}{c|}{ Lottery: TYPE B } \\
\hline prob of & A & prob of B & B & EV \\
A & & & & \\
$50 \%$ & 0.20 & $50 \%$ & 0.20 & 0.20 \\
$50 \%$ & 0.35 & $50 \%$ & 0.35 & 0.35 \\
$30 \%$ & -0.20 & $70 \%$ & 0.70 & 0.43 \\
$50 \%$ & 0.30 & $50 \%$ & 0.30 & 0.30 \\
$50 \%$ & 0.45 & $50 \%$ & 0.45 & 0.45 \\
$30 \%$ & -0.10 & $70 \%$ & 0.80 & 0.53 \\
$70 \%$ & 0.00 & $30 \%$ & 7.00 & 2.10 \\
$40 \%$ & 0.00 & $60 \%$ & 5.00 & 3.00 \\
$50 \%$ & -4.00 & $50 \%$ & 8.00 & 2.00 \\
$30 \%$ & 0.00 & $70 \%$ & 10.00 & 7.00 \\
$70 \%$ & 1.00 & $30 \%$ & 8.00 & 3.10 \\
$40 \%$ & 1.00 & $60 \%$ & 6.00 & 4.00 \\
$50 \%$ & -3.00 & $50 \%$ & 9.00 & 3.00 \\
$30 \%$ & 1.00 & $70 \%$ & 11.00 & 8.00
\end{tabular}

\begin{tabular}{|rrrrrrrrrr}
\hline mean & median & std dev & subj 26 & subj 27 & subj 28 & subj 29 & subj 30 & subj 31 \\
\hline 0.20 & 0.20 & 0.00 & 0.20 & 0.20 & 0.20 & 0.20 & 0.20 & 0.20 \\
0.35 & 0.35 & 0.00 & 0.35 & 0.35 & 0.35 & 0.35 & 0.35 & 0.35 \\
0.49 & 0.50 & 0.21 & 0.65 & 0.50 & 0.70 & 0.10 & 0.50 & 0.50 \\
0.30 & 0.30 & 0.00 & 0.30 & 0.30 & 0.30 & 0.30 & 0.30 & 0.30 \\
0.45 & 0.45 & 0.00 & 0.45 & 0.45 & 0.45 & 0.45 & 0.45 & 0.45 \\
0.62 & 0.60 & 0.12 & 0.70 & 0.60 & 0.50 & 0.80 & 0.60 & 0.50 \\
2.63 & 2.25 & 1.12 & 1.50 & 1.75 & 4.00 & 2.00 & 4.00 & 2.50 \\
2.75 & 2.88 & 0.67 & 2.00 & 3.75 & 2.00 & 3.00 & 3.00 & 2.75 \\
1.58 & 1.75 & 0.49 & 2.00 & 1.50 & 1.00 & 2.00 & 2.00 & 1.00 \\
6.67 & 7.00 & 1.63 & 7.00 & 7.00 & 4.00 & 7.00 & 6.00 & 9.00 \\
1.93 & 1.80 & 0.92 & 1.50 & 2.10 & 1.00 & 3.00 & 3.00 & 1.00 \\
3.21 & 3.00 & 1.19 & 4.50 & 4.75 & 3.00 & 3.00 & 2.00 & 2.00 \\
2.87 & 3.47 & 1.74 & 0.50 & 4.79 & 4.00 & 3.00 & 1.00 & 3.93 \\
8.08 & 8.00 & 2.42 & 8.00 & 7.48 & 10.00 & 8.00 & 4.00 & 11.00 \\
& MUG & & $\mathbf{1 2 . 0 0}$ & $\mathbf{8 . 7 5}$ & $\mathbf{5 . 0 0}$ & $\mathbf{6 . 0 0}$ & $\mathbf{0 . 0 1}$ & $\mathbf{4 . 0 0}$ \\
\hline
\end{tabular}


Summary of Lottery Data

Plott/Zeiler

USC Law School (26 subjects)

Mug valuations measured BEFORE lottery rounds.
Notes: Mug data appears in bold type.

All highlighted offers were made by subjects acting as sellers.

Each column under the heading "individual data" includes

responses for one subject. Type As and Type Bs were

presented with different lotteries (subjects were staggered so that they could not see each other's responses)

\section{April 172001}

\begin{tabular}{|ccccc|}
\hline \multicolumn{5}{c|}{ Lottery: TYPE A } \\
\hline $\begin{array}{c}\text { prob } \\
\text { of A }\end{array}$ & A & prob of & B & BV \\
$50 \%$ & 0.20 & $50 \%$ & 0.20 & 0.20 \\
$50 \%$ & 0.35 & $50 \%$ & 0.35 & 0.35 \\
$30 \%$ & 0.70 & $70 \%$ & -0.20 & 0.07 \\
$50 \%$ & 0.30 & $50 \%$ & 0.30 & 0.30 \\
$50 \%$ & 0.45 & $50 \%$ & 0.45 & 0.45 \\
$30 \%$ & 0.80 & $70 \%$ & -0.10 & 0.17 \\
$70 \%$ & 7.00 & $30 \%$ & 0.00 & 4.90 \\
$40 \%$ & 5.00 & $60 \%$ & 0.00 & 2.00 \\
$50 \%$ & 8.00 & $50 \%$ & -4.00 & 2.00 \\
$30 \%$ & 10.00 & $70 \%$ & 0.00 & 3.00 \\
$70 \%$ & 8.00 & $30 \%$ & 1.00 & 5.90 \\
$40 \%$ & 6.00 & $60 \%$ & 1.00 & 3.00 \\
$50 \%$ & 9.00 & $50 \%$ & -3.00 & 3.00 \\
$30 \%$ & 11.00 & $70 \%$ & 1.00 & 4.00
\end{tabular}

MUG

\begin{tabular}{|c|c|c|c|}
\hline \multicolumn{4}{|c|}{ Individual Data } \\
\hline subj 1 & subj 2 & subj 3 & subj 4 \\
\hline 8.00 & 13.50 & 1.00 & 11.50 \\
\hline
\end{tabular}

summary statistics

mean median std dev

$\begin{array}{lllllll}0.20 & 0.20 & 0.00 & 0.20 & 0.20 & 0.20 & 0.20 \\ 0.35 & 0.35 & 0.00 & 0.35 & 0.35 & 0.35 & 0.35 \\ 0.07 & 0.09 & 0.05 & 0.10 & 0.00 & 0.07 & 0.10 \\ 0.30 & 0.30 & 0.00 & 0.30 & 0.30 & 0.30 & 0.30 \\ 0.45 & 0.45 & 0.00 & 0.45 & 0.45 & 0.45 & 0.45 \\ 0.10 & 0.09 & 0.05 & 0.05 & 0.10 & 0.17 & 0.07 \\ 4.73 & 4.45 & 1.70 & 4.00 & 7.00 & 4.90 & 3.00 \\ 2.31 & 2.13 & 0.47 & 2.00 & 3.00 & 2.00 & 2.25 \\ 1.00 & 1.00 & 0.81 & 1.00 & 1.00 & 2.00 & 0.01 \\ 4.75 & 3.50 & 3.59 & 4.00 & 10.00 & 3.00 & 2.00 \\ 3.83 & 4.50 & 1.96 & 1.00 & 4.00 & 5.30 & 5.00 \\ 2.70 & 3.00 & 0.96 & 3.50 & 3.00 & 3.00 & 1.30 \\ 2.00 & 2.00 & 1.15 & 1.00 & 3.00 & 3.00 & 1.00 \\ 6.25 & 6.00 & 4.03 & 8.00 & 11.00 & 4.00 & 2.00\end{array}$

\begin{tabular}{|ccccc|}
\hline \multicolumn{5}{|c|}{ Lottery: TYPE B } \\
\hline $\begin{array}{c}\text { prob } \\
\text { of A }\end{array}$ & A & prob of & B & EV \\
$50 \%$ & 0.20 & $50 \%$ & 0.20 & 0.20 \\
$50 \%$ & 0.35 & $50 \%$ & 0.35 & 0.35 \\
$30 \%$ & -0.20 & $70 \%$ & 0.70 & 0.43 \\
$50 \%$ & 0.30 & $50 \%$ & 0.30 & 0.30 \\
$50 \%$ & 0.45 & $50 \%$ & 0.45 & 0.45 \\
$30 \%$ & -0.10 & $70 \%$ & 0.80 & 0.53 \\
$70 \%$ & 0.00 & $30 \%$ & 7.00 & 2.10 \\
$40 \%$ & 0.00 & $60 \%$ & 5.00 & 3.00 \\
$50 \%$ & -4.00 & $50 \%$ & 8.00 & 2.00 \\
$30 \%$ & 0.00 & $70 \%$ & 10.00 & 7.00 \\
$70 \%$ & 1.00 & $30 \%$ & 8.00 & 3.10 \\
$40 \%$ & 1.00 & $60 \%$ & 6.00 & 4.00 \\
$50 \%$ & -3.00 & $50 \%$ & 9.00 & 3.00 \\
$30 \%$ & 1.00 & $70 \%$ & 11.00 & 8.00
\end{tabular}

MUG

\begin{tabular}{|ccccc|}
\hline \multicolumn{5}{|c|}{ Individual Data } \\
\hline subj 5 & subj 6 & subj 7 & subj 8 & subj 9 \\
2.00 & $\mathbf{5 . 0 0}$ & $\mathbf{2 . 5 0}$ & $\mathbf{8 . 9 5}$ & $\mathbf{2 . 0 0}$
\end{tabular}

summary statistics

mean median std dev

$\begin{array}{cccccccc}0.20 & 0.20 & 0.00 & 0.20 & 0.20 & 0.20 & 0.20 & 0.20 \\ 0.35 & 0.35 & 0.00 & 0.35 & 0.35 & 0.35 & 0.35 & 0.35 \\ 0.41 & 0.43 & 0.07 & 0.30 & 0.42 & 0.43 & 0.49 & 0.43 \\ 0.30 & 0.30 & 0.00 & 0.30 & 0.30 & 0.30 & 0.30 & 0.30 \\ 0.45 & 0.45 & 0.00 & 0.45 & 0.45 & 0.45 & 0.45 & 0.45 \\ 0.53 & 0.53 & 0.16 & 0.30 & 0.53 & 0.53 & 0.75 & 0.53 \\ 2.08 & 2.10 & 0.04 & 2.00 & 2.10 & 2.10 & 2.10 & 2.10 \\ 2.76 & 3.00 & 0.43 & 2.00 & 3.00 & 3.00 & 2.80 & 3.00 \\ 2.91 & 2.00 & 1.54 & 3.00 & 2.00 & 2.00 & 5.55 & 2.00 \\ 6.80 & 7.00 & 0.45 & 6.00 & 7.00 & 7.00 & 7.00 & 7.00 \\ 2.88 & 3.10 & 0.49 & 2.00 & 3.10 & 3.10 & 3.10 & 3.10 \\ 3.60 & 4.00 & 0.89 & 2.00 & 4.00 & 4.00 & 4.00 & 4.00 \\ 2.40 & 3.00 & 0.89 & 2.00 & 3.00 & 3.00 & 1.00 & 3.00 \\ 7.50 & 8.00 & 2.74 & 3.00 & 8.00 & 8.00 & 10.50 & 8.00\end{array}$




\begin{tabular}{|c|c|c|c|c|}
\hline \multicolumn{5}{|c|}{ Lottery: TYPE A } \\
\hline $\begin{array}{l}\text { prob } \\
\text { of } A\end{array}$ & $A$ & $\begin{array}{c}\text { prob of } \\
\text { B }\end{array}$ & $\mathrm{B}$ & EV \\
\hline $50 \%$ & 0.20 & $50 \%$ & 0.20 & 0.20 \\
\hline $50 \%$ & 0.35 & $50 \%$ & 0.35 & 0.35 \\
\hline $30 \%$ & 0.70 & $70 \%$ & -0.20 & 0.07 \\
\hline $50 \%$ & 0.30 & $50 \%$ & 0.30 & 0.30 \\
\hline $50 \%$ & 0.45 & $50 \%$ & 0.45 & 0.45 \\
\hline $30 \%$ & 0.80 & $70 \%$ & -0.10 & 0.17 \\
\hline $70 \%$ & 7.00 & $30 \%$ & 0.00 & 4.90 \\
\hline $40 \%$ & 5.00 & $60 \%$ & 0.00 & 2.00 \\
\hline $50 \%$ & 8.00 & $50 \%$ & -4.00 & 2.00 \\
\hline $30 \%$ & 10.00 & $70 \%$ & 0.00 & 3.00 \\
\hline $70 \%$ & 8.00 & $30 \%$ & 1.00 & 5.90 \\
\hline $40 \%$ & 6.00 & $60 \%$ & 1.00 & 3.00 \\
\hline $50 \%$ & 9.00 & $50 \%$ & -3.00 & 3.00 \\
\hline $30 \%$ & 11.00 & $70 \%$ & 1.00 & 4.00 \\
\hline
\end{tabular}

\section{April 19, 2001}

\begin{tabular}{|llll|}
\multicolumn{4}{c|}{ Individual Data } \\
\hline subj 10 & subj 11 & subj 12 & subj 13
\end{tabular}

MUG \begin{tabular}{l|l|l|l|l}
\hline 4.50 & 23.00 & 3.50 & 6.25
\end{tabular}

\begin{tabular}{|ccc|}
\hline \multicolumn{3}{|c|}{ summary statistics } \\
\hline mean & median & std dev \\
\hline 0.18 & 0.20 & 0.05 \\
0.35 & 0.35 & 0.00 \\
0.10 & 0.07 & 0.07 \\
0.30 & 0.30 & 0.00 \\
0.45 & 0.45 & 0.00 \\
0.16 & 0.17 & 0.06 \\
3.95 & 4.90 & 1.97 \\
2.25 & 2.00 & 0.50 \\
1.75 & 2.00 & 0.50 \\
3.88 & 3.00 & 2.10 \\
5.33 & 5.83 & 1.06 \\
2.50 & 3.00 & 1.00 \\
2.50 & 3.00 & 1.00 \\
4.56 & 4.13 & 0.97 \\
\end{tabular}

$\begin{array}{llll}0.20 & 0.20 & 0.10 & 0.20 \\ 0.35 & 0.35 & 0.35 & 0.35 \\ 0.07 & 0.07 & 0.20 & 0.07 \\ 0.30 & 0.30 & 0.30 & 0.30 \\ 0.45 & 0.45 & 0.45 & 0.45 \\ 0.17 & 0.08 & 0.22 & 0.17 \\ 4.90 & 1.00 & 5.00 & 4.90 \\ 2.00 & 3.00 & 2.00 & 2.00 \\ 2.00 & 1.01 & 2.00 & 2.00 \\ 3.00 & 7.00 & 2.50 & 3.00 \\ 5.90 & 3.75 & 5.75 & 5.93 \\ 3.00 & 1.00 & 3.00 & 3.00 \\ 3.00 & 1.00 & 3.00 & 3.00 \\ 4.00 & 6.00 & 4.25 & 4.00\end{array}$

MUG

Individual Data

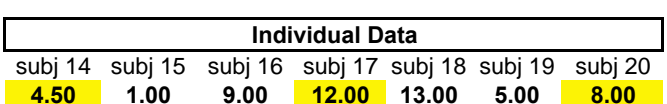

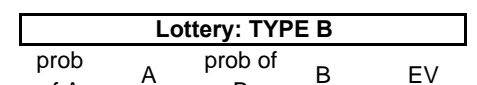

summary statistics

$\begin{array}{ccccc}\begin{array}{c}\text { prob } \\ \text { of A }\end{array} & \text { A } & \begin{array}{c}\text { prob of } \\ \text { B }\end{array} & \text { B } & \text { EV } \\ 50 \% & 0.20 & 50 \% & 0.20 & 0.20 \\ 50 \% & 0.35 & 50 \% & 0.35 & 0.35 \\ 30 \% & -0.20 & 70 \% & 0.70 & 0.43 \\ 50 \% & 0.30 & 50 \% & 0.30 & 0.30 \\ 50 \% & 0.45 & 50 \% & 0.45 & 0.45 \\ 30 \% & -0.10 & 70 \% & 0.80 & 0.53 \\ 70 \% & 0.00 & 30 \% & 7.00 & 2.10 \\ 40 \% & 0.00 & 60 \% & 5.00 & 3.00 \\ 50 \% & -4.00 & 50 \% & 8.00 & 2.00 \\ 30 \% & 0.00 & 70 \% & 10.00 & 7.00 \\ 70 \% & 1.00 & 30 \% & 8.00 & 3.10 \\ 40 \% & 1.00 & 60 \% & 6.00 & 4.00 \\ 50 \% & -3.00 & 50 \% & 9.00 & 3.00 \\ 30 \% & 1.00 & 70 \% & 11.00 & 8.00\end{array}$
mean median std dev

$\begin{array}{lll}0.20 & 0.20 & 0.00 \\ 0.35 & 0.35 & 0.00 \\ 0.49 & 0.45 & 0.12 \\ 0.30 & 0.30 & 0.00 \\ 0.45 & 0.45 & 0.00 \\ 0.35 & 0.40 & 0.19 \\ 2.87 & 3.00 & 1.67 \\ 2.43 & 3.00 & 1.13 \\ 2.64 & 2.00 & 1.77 \\ 7.43 & 7.00 & 1.27 \\ 2.25 & 2.25 & 0.80 \\ 2.41 & 2.00 & 0.89 \\ 2.49 & 3.00 & 1.18 \\ 6.23 & 6.81 & 1.02\end{array}$

$\begin{array}{lllllll}0.20 & 0.20 & 0.20 & 0.20 & 0.20 & 0.20 & 0.20 \\ 0.35 & 0.35 & 0.35 & 0.35 & 0.35 & 0.35 & 0.35 \\ 0.58 & 0.45 & 0.50 & 0.40 & 0.45 & 0.70 & 0.35 \\ 0.30 & 0.30 & 0.30 & 0.30 & 0.30 & 0.30 & 0.30 \\ 0.45 & 0.45 & 0.45 & 0.45 & 0.45 & 0.45 & 0.45 \\ 0.55 & 0.30 & 0.50 & 0.25 & 0.40 & 0.00 & 0.45 \\ 2.10 & 3.00 & 4.00 & 5.00 & 0.01 & 2.00 & 4.00 \\ 3.00 & 3.00 & 3.00 & 3.00 & 0.01 & 2.00 & 3.00 \\ 2.00 & 1.00 & 4.00 & 3.49 & 0.50 & 2.00 & 5.50 \\ 7.00 & 6.00 & 7.00 & 8.00 & 10.00 & 7.00 & 7.00 \\ 2.25 & 1.50 & 3.00 & 2.00 & 1.00 & 3.00 & 3.00 \\ 3.75 & 2.00 & 3.00 & 3.00 & 1.10 & 2.00 & 2.00 \\ 3.00 & 1.00 & 3.50 & 1.75 & 1.15 & 3.00 & 4.00 \\ 5.50 & 5.00 & 7.00 & 6.81 & 7.00 & 7.33 & 5.00\end{array}$




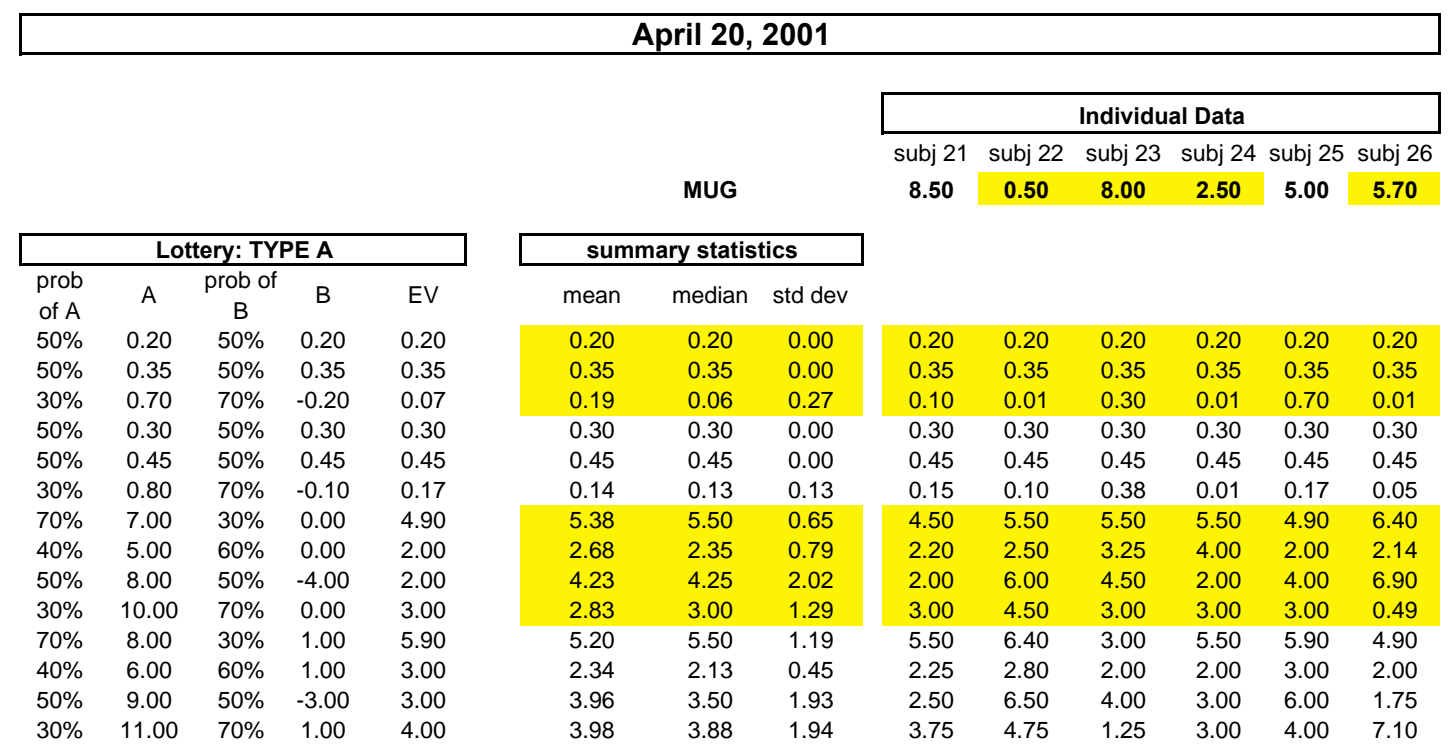

Note: no subjects were presented with Type B lotteries during this session. 
Summary of Lottery Data

Plott/Zeiler

Pasadena Community College (17 subjects)

Mug valuations measured AFTER lottery rounds.
Notes: Mug data appears in bold type.

All highlighted offers were made by subjects acting as sellers. Each column under the heading "individual data" includes responses for one subject. Type As and Type Bs were presented with different lotteries (subjects were staggered so that they could not see each other's responses)

\begin{tabular}{|c|c|c|c|c|c|c|c|c|c|c|c|c|c|}
\hline \multicolumn{14}{|c|}{ February 4, 2002} \\
\hline \multicolumn{5}{|c|}{ Lottery: TYPE A } & \multicolumn{3}{|c|}{ summary statistics } & \multicolumn{6}{|c|}{ Individual Data } \\
\hline $\begin{array}{c}\text { prob of } \\
\text { A }\end{array}$ & A & prob of B & B & EV & mean & median & std dev & subj 1 & subj 2 & subj 3 & subj 4 & subj 5 & subj 6 \\
\hline $50 \%$ & 0.20 & $50 \%$ & 0.20 & 0.20 & 0.20 & 0.20 & 0.00 & 0.20 & 0.20 & 0.20 & 0.20 & 0.20 & 0.20 \\
\hline $50 \%$ & 0.35 & $50 \%$ & 0.35 & 0.35 & 0.34 & 0.35 & 0.02 & 0.35 & 0.35 & 0.35 & 0.30 & 0.35 & 0.35 \\
\hline $30 \%$ & 0.70 & $70 \%$ & -0.20 & 0.07 & 0.44 & 0.40 & 0.25 & 0.20 & 0.75 & 0.30 & 0.50 & 0.20 & 0.70 \\
\hline $50 \%$ & 0.30 & $50 \%$ & 0.30 & 0.30 & 0.28 & 0.30 & 0.03 & 0.30 & 0.25 & 0.30 & 0.30 & 0.25 & 0.30 \\
\hline $50 \%$ & 0.45 & $50 \%$ & 0.45 & 0.45 & 0.48 & 0.45 & 0.04 & 0.45 & 0.55 & 0.45 & 0.45 & 0.50 & 0.45 \\
\hline $30 \%$ & 0.80 & $70 \%$ & -0.10 & 0.17 & 0.48 & 0.48 & 0.35 & 0.00 & 1.00 & 0.20 & 0.50 & 0.70 & 0.45 \\
\hline $70 \%$ & 7.00 & $30 \%$ & 0.00 & 4.90 & 6.42 & 6.75 & 0.80 & 5.00 & 7.00 & 6.50 & 6.00 & 7.00 & 7.00 \\
\hline $40 \%$ & 5.00 & $60 \%$ & 0.00 & 2.00 & 4.50 & 4.75 & 0.77 & 3.00 & 4.50 & 4.50 & 5.00 & 5.00 & 5.00 \\
\hline $50 \%$ & 8.00 & $50 \%$ & -4.00 & 2.00 & 5.33 & 5.50 & 1.21 & 4.00 & 6.00 & 4.00 & 5.00 & 7.00 & 6.00 \\
\hline $30 \%$ & 10.00 & $70 \%$ & 0.00 & 3.00 & 7.00 & 7.00 & 2.83 & 5.00 & 8.00 & 3.00 & 6.00 & 10.00 & 10.00 \\
\hline $70 \%$ & 8.00 & $30 \%$ & 1.00 & 5.90 & 5.92 & 5.75 & 1.11 & 5.00 & 6.00 & 5.00 & 6.00 & 8.00 & 5.50 \\
\hline $40 \%$ & 6.00 & $60 \%$ & 1.00 & 3.00 & 3.50 & 3.50 & 1.18 & 3.00 & 4.00 & 2.50 & 5.00 & 4.50 & 2.00 \\
\hline $50 \%$ & 9.00 & $50 \%$ & -3.00 & 3.00 & 6.22 & 6.00 & 1.18 & 7.00 & 8.00 & 4.50 & 5.80 & 6.00 & 6.00 \\
\hline \multirow[t]{2}{*}{$30 \%$} & 11.00 & $70 \%$ & 1.00 & 4.00 & 5.63 & 3.88 & 4.25 & 2.00 & 11.00 & 2.00 & 4.25 & 11.00 & 3.50 \\
\hline & & & & & \multicolumn{3}{|c|}{ MUG } & 3.00 & 3.50 & 6.00 & 8.78 & 5.00 & 8.50 \\
\hline \multicolumn{5}{|c|}{ Lottery: TYPE B } & \multicolumn{3}{|c|}{ summary statistics } & \multicolumn{6}{|c|}{ Individual Data } \\
\hline $\begin{array}{c}\text { prob of } \\
A\end{array}$ & A & prob of B & B & EV & mean & median & std dev & subj 7 & subj 8 & subj 9 & subj 10 & subj 11 & subj 12 \\
\hline $50 \%$ & 0.20 & $50 \%$ & 0.20 & 0.20 & 0.20 & 0.20 & 0.00 & 0.20 & 0.20 & 0.20 & 0.20 & 0.20 & 0.20 \\
\hline $50 \%$ & 0.35 & $50 \%$ & 0.35 & 0.35 & 0.35 & 0.35 & 0.00 & 0.35 & 0.35 & 0.35 & 0.35 & 0.35 & 0.35 \\
\hline $30 \%$ & -0.20 & $70 \%$ & 0.70 & 0.43 & 0.43 & 0.48 & 0.12 & 0.50 & 0.40 & 0.45 & 0.50 & 0.20 & 0.50 \\
\hline $50 \%$ & 0.30 & $50 \%$ & 0.30 & 0.30 & 0.30 & 0.30 & 0.00 & 0.30 & 0.30 & 0.30 & 0.30 & 0.30 & 0.30 \\
\hline $50 \%$ & 0.45 & $50 \%$ & 0.45 & 0.45 & 0.44 & 0.45 & 0.02 & 0.45 & 0.45 & 0.45 & 0.40 & 0.45 & 0.45 \\
\hline $30 \%$ & -0.10 & $70 \%$ & 0.80 & 0.53 & 0.42 & 0.45 & 0.17 & 0.65 & 0.40 & 0.25 & 0.50 & 0.20 & 0.50 \\
\hline $70 \%$ & 0.00 & $30 \%$ & 7.00 & 2.10 & 2.92 & 3.00 & 2.42 & 3.00 & 3.50 & 1.00 & 3.00 & 0.00 & 7.00 \\
\hline $40 \%$ & 0.00 & $60 \%$ & 5.00 & 3.00 & 2.79 & 2.88 & 1.41 & 2.75 & 3.00 & 0.75 & 2.00 & 3.25 & 5.00 \\
\hline $50 \%$ & -4.00 & $50 \%$ & 8.00 & 2.00 & 3.58 & 4.00 & 1.63 & 4.00 & 2.00 & 1.50 & 4.00 & 6.00 & 4.00 \\
\hline $30 \%$ & 0.00 & $70 \%$ & 10.00 & 7.00 & 5.92 & 6.38 & 2.72 & 6.75 & 6.00 & 3.00 & 7.00 & 2.75 & 10.00 \\
\hline $70 \%$ & 1.00 & $30 \%$ & 8.00 & 3.10 & 2.63 & 2.50 & 0.85 & 3.00 & 2.00 & 1.80 & 3.00 & 2.00 & 4.00 \\
\hline $40 \%$ & 1.00 & $60 \%$ & 6.00 & 4.00 & 3.12 & 3.25 & 1.87 & 3.50 & 3.00 & 1.20 & 4.00 & 1.00 & 6.00 \\
\hline $50 \%$ & -3.00 & $50 \%$ & 9.00 & 3.00 & 2.67 & 2.50 & 0.82 & 3.00 & 4.00 & 2.00 & 2.00 & 2.00 & 3.00 \\
\hline \multirow[t]{2}{*}{$30 \%$} & 1.00 & $70 \%$ & 11.00 & 8.00 & 5.71 & 5.25 & 1.44 & 6.75 & 5.00 & 5.00 & 5.50 & 4.00 & 8.00 \\
\hline & & & & & & MUG & & 8.50 & 10.00 & 3.00 & 5.85 & 10.00 & 5.00 \\
\hline
\end{tabular}


February 5, 2002

\begin{tabular}{|ccccc|}
\hline \multicolumn{5}{|c|}{ Lottery: TYPE A } \\
\hline prob of & A & prob of B & B & EV \\
A & & & & \\
$50 \%$ & 0.20 & $50 \%$ & 0.20 & 0.20 \\
$50 \%$ & 0.35 & $50 \%$ & 0.35 & 0.35 \\
$30 \%$ & 0.70 & $70 \%$ & -0.20 & 0.07 \\
$50 \%$ & 0.30 & $50 \%$ & 0.30 & 0.30 \\
$50 \%$ & 0.45 & $50 \%$ & 0.45 & 0.45 \\
$30 \%$ & 0.80 & $70 \%$ & -0.10 & 0.17 \\
$70 \%$ & 7.00 & $30 \%$ & 0.00 & 4.90 \\
$40 \%$ & 5.00 & $60 \%$ & 0.00 & 2.00 \\
$50 \%$ & 8.00 & $50 \%$ & -4.00 & 2.00 \\
$30 \%$ & 10.00 & $70 \%$ & 0.00 & 3.00 \\
$70 \%$ & 8.00 & $30 \%$ & 1.00 & 5.90 \\
$40 \%$ & 6.00 & $60 \%$ & 1.00 & 3.00 \\
$50 \%$ & 9.00 & $50 \%$ & -3.00 & 3.00 \\
$30 \%$ & 11.00 & $70 \%$ & 1.00 & 4.00
\end{tabular}

\begin{tabular}{|c|c|c|c|c|c|}
\hline \multicolumn{3}{|c|}{ summary statistics } & \multicolumn{3}{|c|}{ Individual Data } \\
\hline mean & median & std dev & subj 13 & subj 14 & subj 15 \\
\hline 0.20 & 0.20 & 0.00 & 0.20 & 0.20 & 0.20 \\
\hline 0.35 & 0.35 & 0.00 & 0.35 & 0.35 & 0.35 \\
\hline 0.42 & 0.40 & 0.08 & 0.35 & 0.50 & 0.40 \\
\hline 0.30 & 0.30 & 0.00 & 0.30 & 0.30 & 0.30 \\
\hline 0.45 & 0.45 & 0.00 & 0.45 & 0.45 & 0.45 \\
\hline 0.35 & 0.35 & 0.05 & 0.35 & 0.30 & 0.40 \\
\hline 4.50 & 4.00 & 1.80 & 4.00 & 3.00 & 6.50 \\
\hline 2.67 & 2.00 & 1.15 & 2.00 & 2.00 & 4.00 \\
\hline 2.67 & 2.00 & 1.15 & 2.00 & 2.00 & 4.00 \\
\hline 2.33 & 3.00 & 1.15 & 3.00 & 3.00 & 1.00 \\
\hline 3.67 & 5.00 & 2.31 & 5.00 & 5.00 & 1.00 \\
\hline 2.50 & 2.50 & 1.50 & 4.00 & 2.50 & 1.00 \\
\hline 4.67 & 6.00 & 3.21 & 6.00 & 7.00 & 1.00 \\
\hline \multirow[t]{2}{*}{4.67} & 4.00 & 1.15 & 4.00 & 4.00 & 6.00 \\
\hline & MUG & & 8.00 & 3.50 & 2.50 \\
\hline \multicolumn{3}{|c|}{ summary statistics } & \multicolumn{2}{|c|}{ Individual Data } & \\
\hline mean & median & std dev & subj 16 & subj 17 & \\
\hline 0.19 & 0.19 & 0.01 & 0.18 & 0.20 & \\
\hline 0.33 & 0.33 & 0.04 & 0.30 & 0.35 & \\
\hline 0.71 & 0.71 & 0.01 & 0.71 & 0.70 & \\
\hline 0.30 & 0.30 & 0.00 & 0.30 & 0.30 & \\
\hline 0.43 & 0.43 & 0.04 & 0.40 & 0.45 & \\
\hline 0.61 & 0.61 & 0.16 & 0.72 & 0.50 & \\
\hline 4.00 & 4.00 & 4.24 & 7.00 & 1.00 & \\
\hline 3.38 & 3.38 & 1.94 & 4.75 & 2.00 & \\
\hline 5.88 & 5.88 & 2.65 & 7.75 & 4.00 & \\
\hline 7.75 & 7.75 & 3.18 & 10.00 & 5.50 & \\
\hline 2.78 & 2.78 & 1.10 & 2.00 & 3.55 & \\
\hline 3.63 & 3.63 & 0.53 & 3.25 & 4.00 & \\
\hline 4.29 & 4.29 & 1.00 & 5.00 & 3.58 & \\
\hline 8.50 & 8.50 & 0.71 & 9.00 & 8.00 & \\
\hline & MUG & & 7.50 & 7.50 & \\
\hline
\end{tabular}




\begin{tabular}{|c|c|c|c|}
\hline Round \# & Lottery for Type A & Lottery for Type B & $\begin{array}{c}\text { Range for Fixed } \\
\text { Offer }\end{array}$ \\
\hline Round 1 & $(0.5, .20,0.5, .20)$ & $(0.5, .20,0.5, .20)$ & {$[0.00-0.99]$} \\
\hline Round 2 & $(0.5, .35,0.5, .35)$ & $(0.5, .35,0.5, .35)$ & {$[0.00-0.99]$} \\
\hline Round 3 & $(0.3, .70,0.7,-.20)$ & $(0.3,-.20,0.7, .70)$ & {$[0.00-0.99]$} \\
\hline Round 4 & $(0.5, .30,0.5, .30)$ & $(0.5, .30,0.5, .30)$ & {$[0.00-0.99]$} \\
\hline Round 5 & $(0.5, .45,0.5, .45)$ & $(0.5, .45,0.5, .45)$ & {$[0.00-0.99]$} \\
\hline Round 6 & $(0.3, .80,0.7,-.10)$ & $(0.7, .80,0.3,-.10)$ & {$[0.00-0.99]$} \\
\hline Round 7 & $(0.7,7.00,0.3,0.00)$ & $(0.3,0.00,0.7,7.00)$ & {$[0.00-8.00]$} \\
\hline Round 8 & $(0.4,5.00,0.6,0.00)$ & $(0.4,0.00,0.6,5.00)$ & {$[0.00-6.00]$} \\
\hline Round 9 & $(0.5,8.00,0.5,-4.00)$ & $(0.5,-4.00,0.5,8.00)$ & {$[0.00-9.00]$} \\
\hline Round 10 & $(0.3,10.00,0.7,0.00)$ & $(0.3,0.00,0.7,10.00)$ & {$[0.00-11.00]$} \\
\hline Round 11 & $(0.7,8.00,0.3,1.00)$ & $(0.7,1.00,0.3,8.00)$ & {$[0.00-9.00]$} \\
\hline Round 12 & $(0.4,6.00,0.6,1.00)$ & $(0.4,1.00,0.6,6.00)$ & {$[0.00-7.00]$} \\
\hline Round 13 & $(0.5,9.00,0.5,-3.00)$ & $(0.5,-3.00,0.5,9.00)$ & {$[0.00-10.00]$} \\
\hline Round 14 & $(0.3,11.00,0.7,1.00)$ & $(0.3,1.00,0.7,11.00)$ & {$[0.00-12.00]$} \\
\hline
\end{tabular}

Note: Subjects did not know range of distributions. 